\title{
A systematic framework for energetic, environmental and economic (3E) assessment and design of polygeneration systems
}

\author{
Kok Siew $\mathrm{Ng}^{a, *}$, Elias Martinez Hernandez ${ }^{b}$ \\ a Centre for Environmental Strategy, University of Surrey, Guildford GU2 7XH, UK \\ ${ }^{b}$ Department of Engineering Science, University of Oxford, Oxford OX1 3PJ, UK
}

\section{A R T I C L E I N F O}

\section{Article history:}

Received 26 March 2015

Received in revised form 18

November 2015

Accepted 24 November 2015

Available online 9 December 2015

Keywords:

Process design and integration

Performance metric

Multi-criteria analysis

Integrated assessment

Sustainability and circular economy

Sustainable energy system

\begin{abstract}
A B S T R A C T
The replacement of traditional process design approach by a more holistic approach is exigent in view of developing sustainable industrial systems and effectively reducing the energy and emission intensities in the process industries. Polygeneration systems are flexible and integrated multi-product systems that can potentially enhance energy efficiency, minimise financial risk and mitigate environmental impact. This paper presents a systematic conceptual process design and decision-making framework for facilitating multi-criteria analysis and selection of design options by considering three major criteria at process level-energy, environment and economy (3E). In this framework, three major steps are carried out: (i) defining system boundary, (ii) performance evaluation on the inner and outer system boundaries, (iii) 3E performance evaluation. 3E metric is proposed and it is derived from the relative economic worthiness associated with process energy intensity, greenhouse gas intensity and energy recovery which collectively indicates the techno-economic and environmental performances of a system with respect to the base case system. The methodology has been demonstrated through methanol and electricity production system with eight alternative configurations. Among the configurations under consideration, high offgas recycle for methanol production followed by electricity generation in series configuration has been found to carry the best $3 \mathrm{E}$ performance.

(C) 2015 The Institution of Chemical Engineers. Published by Elsevier B.V. All rights reserved.
\end{abstract}

\section{Introduction}

Stepping into the 21st century, energy has become the global focal point on the subjects of securing resources at the socioeconomic level; enhancing energy efficiency and recovering energy from waste at the technological level; and reducing greenhouse gas emissions at the environmental level. Global warming is concomitant with soaring energy demand and thus $\mathrm{CO}_{2}$ mitigation is one of the major efforts urgently needed in lessening environmental impact from process industries. Process industries such as energy, chemical, refinery and manufacturing industries are major consumers of energy and sources of $\mathrm{CO}_{2}$ emission. The Sustainable Process Industry through Resource and Energy Efficiency (SPIRE) partnership is targeting to reduce energy consumption in the process industry by $30 \%$ and reduce utilisation of non-renewable raw materials by $20 \%$ to address the challenges in sustainability and competitiveness in process industry within the European continent (Sustainable Process Industry through Resource and Energy Efficiency (SPIRE), 2012). This shows that the notion of sustainability has penetrated the process industries in recent years and new technologies and design methodologies are called upon to tackle the challenges (Sadhukhan et al., 2014; Wan Alwi et al., 2014).

In the context of rising concerns over sustainability of industrial systems, process integration has become an

\footnotetext{
* Corresponding author. Tel.: +44 (0) 7919074975.

E-mail addresses: k.ng@surrey.ac.uk, kok_siew@hotmail.com (K.S. Ng). http://dx.doi.org/10.1016/j.cherd.2015.11.017

0263-8762/@ 2015 The Institution of Chemical Engineers. Published by Elsevier B.V. All rights reserved.
} 
important technique in upgrading existing systems and also designing new systems to achieve higher energy efficiency, maximum utilisation of resources and lower environmental impact (Klemeš et al., 2011). Mass (El-Halwagi, 2012) and energy integration (Smith, 2005) are well-established techniques and have been widely adopted in the process industries. Achieving high level of resource efficiency and process flexibility in polygeneration systems through extensive process integration has been regarded as a promising strategy in addressing the needs in the process industries with regard to improving energy and economic performances while reducing environmental impacts (Serra et al., 2009). Polygeneration system is an integrated energy system that provides a flexible platform in generating multiple products such as transportation fuels, chemicals, heat and power from various types of feedstocks such as coal, biomass, bio-oil and natural gas, which is more advanced than cogeneration and trigeneration systems. Refinery and petrochemical plants are examples of traditional polygeneration systems, of which the systems generate fuels, chemicals and energy products from crude oil. Polygeneration, in the modern context should be able to demonstrate these features: (i) highly flexible in terms of product generation and feedstock utilisation; (ii) well integrated and highly energy efficient; (iii) high economic performance; (iv) environmental benign; (v) achieving maximum resource utilisation through recycling and reuse; and (vi) integrated with waste recovery facilities for value-added production. Process flexibility is crucial for industrial systems as it minimises financial risk and improves energy security by avoiding reliance on a specific type of feedstock, and thus the systems are more resilient and adaptable to changes in market demands and prices. The concept of trigeneration is commonly and strictly referred to generation of power, heating and cooling only, and it is the basic form of polygeneration (Lozano et al., 2009). Polygeneration has the advantage of reducing the trading of utilities by offering a self-satisfied environment through on-site generation of heating and cooling requirement and in-situ energy recovery within the integrated facilities (Ng, 2011). Therefore, energy efficiency of polygeneration system is expected to be higher than a single production plant due to the high degree of process integration among the processes. Utilisation of renewable feedstock such as biomass in polygeneration system is highly envisaged considering that the system could offer significant benefits such as enhanced overall efficiency and lower greenhouse gas (GHG) emissions (Sadhukhan et al., 2014). Integrating carbon capture and storage (CCS) or $\mathrm{CO}_{2}$ reuse units within the polygeneration system is expected to be more cost-effective at large-scale production. Polygeneration concept also considers resource recovery such as metals and chemicals from wastes, relevant to the recent advocates in circular economy. All these benefits have driven polygeneration to become an important subject in modern engineering discipline. The concept is highly relevant and important in developing sustainable process industries as well as urban planning and management.

Significant research development can be seen recently in the field of polygeneration. Yamashita and Barreto (2005) investigated the co-production of hydrogen, Fischer-Tropsch fuel, methanol and electricity, in different combination of products through a coal gasification system, with and without $\mathrm{CO}_{2}$ capture. The results have shown that co-production system is economically compelling compared to single production, however it must be analysed on a case-by-case basis for its technical and economic feasibilities. $\mathrm{Ng}$ et al.
(2013) conducted techno-economic analyses on various coal gasification based polygeneration systems coupled with either carbon capture and storage unit or $\mathrm{CO}_{2}$ reuse unit, while incorporating energy integration design strategies to enhance the overall system performance. Yi et al. (2014) proposed a dualgas polygeneration system which combined a gasifier unit and a reforming unit, employing two different feedstocks, i.e. coke oven gas and coal, and incorporated $\mathrm{CO}_{2}$ recycling strategy, for methanol and power production. The proposed system has the potential of minimising resource and utility consumptions while reducing $\mathrm{CO}_{2}$ emission, demonstrated through energy, environment and economy evaluation and comparison with other conventional technologies such as integrated gasification combined cycle (IGCC). Although current interests on polygeneration in most countries such as China and the US are focusing on using coal (Zhang et al., 2014) and shale gas (Khojasteh Salkuyeh and Adams, 2015) as the primary feedstocks, polygeneration system using renewable feedstock is more desirable in terms of achieving greater environmental benefits in long-term perspective. Solar thermal gasification of biomass (Bai et al., 2015), gasification of bio-oil ( $\mathrm{Ng}$ and Sadhukhan, 2011) and agricultural residue such as rice straw (Jana and De, 2015) have been investigated and have shown promising results in terms of thermodynamic, economic and environmental performances.

A number of researchers have developed mathematical programming methods which are useful in tackling the challenges in the design and synthesis of complex polygeneration system. Liu et al. (2007) developed a superstructural and mixed integer programming approach for selecting polygeneration system with optimum profit margin by considering various technologies, feedstocks and products in a gasification model. Carvalho et al. (2012) has extended the application of trigeneration concept to non-industrial sector. An optimum configuration of trigeneration system to be installed in a hospital has been determined using an integrated energy-planning framework incorporating mixed integer linear programming (MILP) method which takes into account both economic and environmental criteria. Ubando et al. (2013) proposed a fuzzy fractional programming model with the consideration of allocating carbon footprint to each energy stream in a trigeneration system. Lozano et al. (2014) developed an integrated methodology that incorporates thermodynamic, economic and environmental analyses, and applied on a trigeneration system in buildings within the residential-commercial sector. Identifying bottlenecks in polygeneration system has been a challenge and this can be dealt using algebraic approach proposed by Tan et al. (2012). Tan et al. (2014) has further addressed the challenges due to process inoperability using P-graph approach, alternative to mathematical programming approach using MILP method developed by Kasivisvanathan et al. (2013) to determine the optimum adjustments in polygeneration system. Economic performance is often being used as the key indicator in deciding the feasibility of a project in any process industry. However, the emergence of sustainability concept in recent years has changed the way a decision is being made as environment and societal criteria must now be taken into account (Azapagic, 2010). This also implies that traditional methods of process design should be revamped to suit these sustainability criteria. A combinatorial analytical methodology comprising of economic value and environmental impact (EVEI) assessment was developed and demonstrated in a bioethanol production case study (Martinez-Hernandez et al., 2013). Three-dimensional 
sustainability metrics which consider economy, ecology and society were proposed for the evaluation of energy intensity, material intensity, potential chemical risk, and potential environmental impact in chemical production processes (Martins et al., 2006). GREENSCOPE methodology was developed by US Environmental Protection Agency, taking into account energy, efficiency, environment and economy as the sustainability criteria for examining the sustainability of chemical processes, quantified using a scoring scale (Gonzalez and Smith, 2003). Most of these methodologies have adopted mathematical programming approach and have examined the system performance using conventional evaluation methods. Large amount of data is still required to carry out the analysis using the existing methodologies and yet the results generated do not necessarily provide sufficient insights into the system performance with respect to energy, environmental and economic aspects. Hence, there is an urgent need to address the limitations of the existing methodologies and to develop a simplified and more holistic assessment for determining the performance of polygeneration system.

Designing polygeneration systems requires a more sophisticated, holistic and systematic methodology to address the complex interaction among the processes and the variables involved. The selection of product combination in a polygeneration system is vital in determining its economic viability (Yamashita and Barreto, 2005). The challenge thus lies on the selection of an energy efficient, environmental benign and economical production pathway and system configuration. Furthermore, it is often difficult to optimise energy, environmental and economic performances simultaneously and hence a metric needs to be defined to facilitate such multi-criteria analysis and optimisation. A methodology that systematises the combined evaluation of energy, environmental and economic performances of process alternatives is crucial for designing polygeneration systems, prior to the detailed process design stage. This is the first dedicated paper of employing a combined graphical and multifaceted quantitative assessment method in analysing the performance of a selection of polygeneration system configurations. Systematic conceptual process design methodology and a performance indicator have been developed to facilitate the analysis and selection of design options for polygeneration systems with the consideration of energy, environment and economy criteria. The proposed methodology is less data intensive and allows decision makers to intervene and gain insights at every point of decision during the evolution of a polygeneration system design. Thus, the novelty lies in the simplification of the methodology, and thus resulting in more robust and effective decision-making process for polygeneration system design at the conceptual stage. Furthermore, the results generated using the proposed $3 \mathrm{E}$ performance metric are more adaptable and convincing to stakeholders, engineers, investors and policy makers in various industrial sectors, such as biorefinery, petroleum refinery, chemical and energy production plants. The application of this methodology is demonstrated through a gasification system with methanol and electricity production with various configurations such as once-through, recycle, series, parallel and parallel-series configurations. Current methodology has shown significant improvement over the existing methodologies in addressing complex polygeneration system problems in the preliminary conceptual process design stage. Screening of a selection of process configurations can be performed effectively while avoiding the needs of costing and environmental modelling software. Overall system performances with respect to energy, environmental and economic aspects can be quantitatively measured using the proposed multi-criteria assessment and $3 \mathrm{E}$ metric. In addition, data requirement in the current analysis has been reduced significantly compared to conventional techno-economic and life cycle analyses.

This paper is structured as follows. The conceptual design methodology is explained in detail in Section 2. Section 3 presents the analysis of eight case studies using the proposed methodology. The results from the analysis are discussed in Section 4. The proposed methodology, analysis and findings are summarised in Section 5.

\section{Methodology}

Section 2.1 presents the proposed conceptual design framework consisting of scope definition, $3 \mathrm{E}$ assessment and the comparison and decision-making stages. $3 \mathrm{E}$ assessment is discussed in detail in Section 2.2.

\subsection{Conceptual design framework for polygeneration systems}

A systematic conceptual process design strategy is proposed, in which a decision-making framework is embodied, with the aim to facilitate the design of polygeneration system followed by comparison of system performance among various design options. The proposed methodology is shown in Fig. 1 and explained as follows:

- Scope definition: The scope of analysis is only focused on the selected boundary of study. The boundary of study in question is a specific region that has been identified on the system where major improvement can be made. The problem size to be investigated is thus greatly reduced but the main challenge is the identification of the key boundary of study where experience and some heuristics are required. This will be demonstrated and elucidated in Section 3.

- 3E assessment: The 3E (Energy, Environment and Economy) assessment is introduced to perform a holistic evaluation by taking into account different performance criteria while simplifying the whole decision-making process in conceptual process design. The proposed 3E assessment comprises three major steps: process modelling, outside boundary (OB) analysis and inside boundary (IB) analysis. It should be noted that process modelling in the assessment is only limited to the boundary of study and not the entire system. Therefore, the data and time required for the analysis and decision-making process are less compared to the conventional process design approach. The details of the assessment will be discussed in Section 2.2.

- Comparison and decision: The 3E assessment can sufficiently justify the performance of the design options and the decision can be made without going through detailed design stage.

\subsection{Energy, environment and economy (3E) assessment}

The assessment framework accounts for three main aspects: Energy, Environment and Economy and it is thus referred to as "3E assessment". The advantages of $3 \mathrm{E}$ assessment are

- Only information that is easily obtainable is required. 


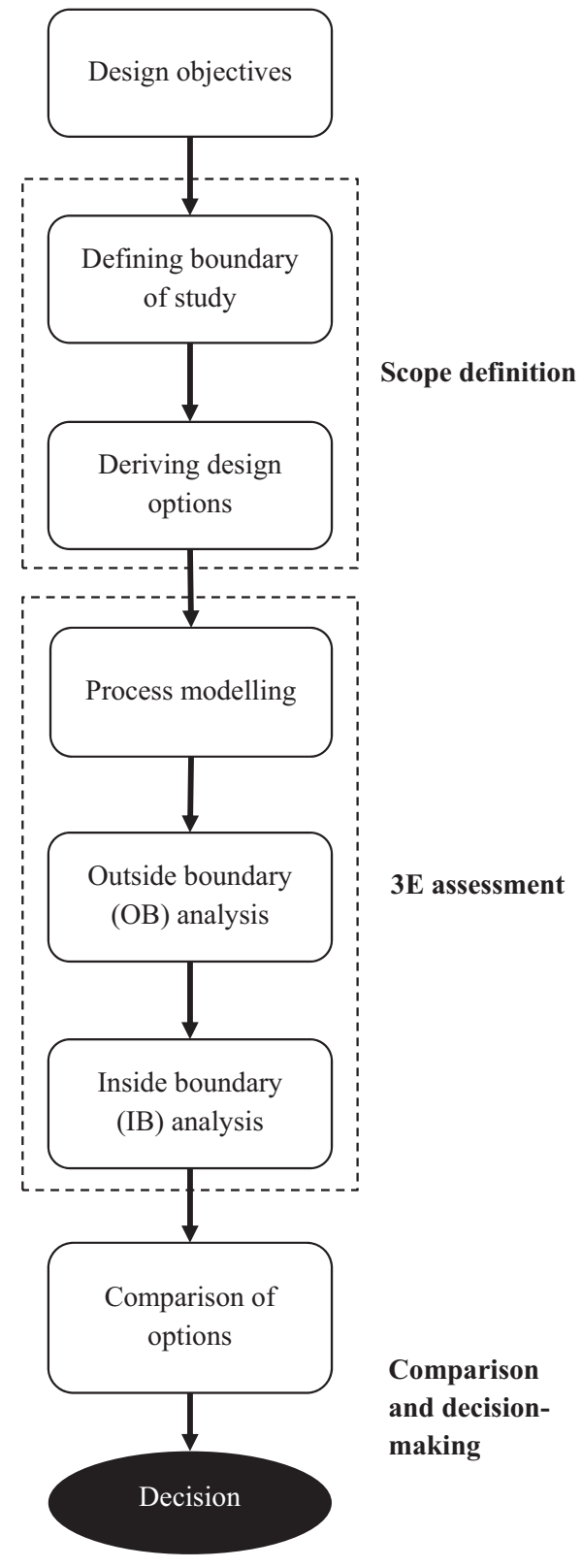

Fig. 1 - Proposed systematic conceptual process design framework. 3E refers to energy, environment and economy.

- Cost correlations and external software for detailed economic evaluation (e.g. Aspen Icarus) are not required.

- Providing an integral assessment on energy, economic and environmental performances of various design options.

- A more systematic and robust process design approach in screening design options.

Note that the main focus of the $3 \mathrm{E}$ assessment is to investigate different production routes and configurations, while there is less emphasis on the operating conditions and type of equipment. It should be reminded that comparison should be made on a like-to-like basis using same type of equipment for the same functionality to avoid complications during analysis, in particularly economic analysis.

The 3E assessment framework is illustrated in Fig. 2 and consists of three major steps, explained as follows.

\subsubsection{Process modelling}

Process modelling is performed on the selected boundary of study by means of either simulation or mathematical modelling. In the current study, Aspen Plus has been chosen as the modelling tool. The purpose of carrying out process modelling is to obtain the mass and energy information associated with the feed and product streams as well as the process units within the boundary of the system under consideration, which are required in the subsequent analyses.

\subsubsection{Outside boundary (OB) analysis}

Outside boundary $(\mathrm{OB})$ refers to the region embracing the selected section of a system within the boundary of study. OB analysis serves as a preliminary tool for predicting the performance of a particular design option compared to the base case. This analysis only considers the energy and economic values of the feed and product as well as emission at the outer boundary of system, while omitting the details inside the boundary of system. Nevertheless, it provides a hint or direction of which a particular design option is potentially more favourable or feasible compared to the others, though conclusion is yet to be drawn at this point. The economic $(E c)$ and energy value ratios $(E n)$, defined in Eqs. (1) and (2), respectively, provide implications on the performance of the selected boundary of system, based on the information on the flows that cross the boundary of the system, i.e. feed and product. The terms "economic efficiency" and "energy efficiency" are avoided since they might lead to confusion that relates to the overall system, which is not the case in this context.

Economic value ratio, $E c=\frac{\text { Economic value of product }}{\text { Economic value of feed }}$

Energy value ratio, $E n=\frac{\text { Energy value of product }}{\text { Energy value of feed }}$

where economic value of product/feed is the flow rate multiplied by the corresponding price. Similarly, energy value of product/feed is the flow rate multiplied by the corresponding lower heating value.

It is more convenient to assess the feasibility and favourability of the design options using a plot named as "Production Feasibility Plot" in the present context, where Ec is plotted against En, shown in Fig. 3.

There are essentially three main zones on the Production Feasibility Plot. The zones are partitioned at points $E c=1$ and $E n=1 . E c=1$ suggests that the product value is equal to the feed value and thus it sets the minimum economic value for a favourable production. Technically speaking, $E n=1$ sets the upper boundary of a feasible production because the product energy value should not exceed the feed energy value, according to the law of conservation of energy. With these rationales in mind, a feasible and favourable production should fall somewhere below and as close as possible to $E n=1$. The favourability of a design option increases with increasing Ec. Fig. 3 indicates that zones $A$ and $B$ are the feasible regions with zone A being the most favourable one. The infeasible region is shaded as shown in Fig. 3. The following rules can be adopted when interpreting the Production Feasibility Plot:

- Up-right rule: Any modification or new design should result in an increase in both $E c$ and En, i.e. it can only be shifted upwards and towards the right with reference to the original point of the base case. 
Process Modelling

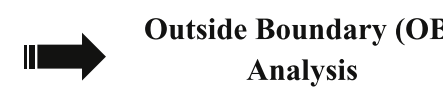

Inside Boundary (IB) Analysis

\begin{tabular}{|c|c|c|}
\hline \begin{tabular}{l}
\multicolumn{1}{c}{ Objective } \\
- To extract mass and \\
energy balances from \\
streams and process \\
units.
\end{tabular} & $\begin{array}{l}\text { Objective } \\
\text { - To generate a hypothesis } \\
\text { that indicates the } \\
\text { "likely" design options } \\
\text { and the direction for } \\
\text { further investigation. }\end{array}$ & $\begin{array}{l}\text { Objective } \\
\text { - To evaluate the } \\
\text { performance of each } \\
\text { option. }\end{array}$ \\
\hline $\begin{array}{l}\text { Method } \\
\text { - Simulation / } \\
\text { mathematical modelling }\end{array}$ & $\begin{array}{l}\text { Method } \\
\text { - Calculate energy value } \\
\text { ratio, economic value } \\
\text { ratio and GHG } \\
\text { emissions } \\
\text { - Generate Production } \\
\text { Feasibility Plot } \\
\text { (Graphical method) }\end{array}$ & $\begin{array}{l}\text { Method } \\
\text { - } \text { Process energy intensity } \\
\text { assessment } \\
\text { - Process GHG intensity } \\
\text { assessment } \\
\text { - Process recoverable } \\
\text { energy assessment } \\
\text { - Economic analysis using } \\
\text { scale factor method }\end{array}$ \\
\hline \begin{tabular}{l}
\multicolumn{1}{c}{ Data } \\
(Generated/Specified) \\
- Feed quantity/flow rate \\
- Product quantity/flow \\
rate \\
- Feed composition \\
- GHG emission \\
- GHG in feed \\
- Power consumption by \\
- process unit \\
Power generation by \\
- Heat consumption by \\
- process unit \\
procest generation by
\end{tabular} & \begin{tabular}{l}
\multicolumn{1}{c}{$\begin{array}{c}\text { Data } \\
\text { (Required) }\end{array}$} \\
- Feed quantity/flow rate \\
- $\begin{array}{l}\text { Product quantity/flow } \\
\text { rate }\end{array}$ \\
- Energy value of feed \\
- Energy value of product \\
- Economic value of feed \\
- Economic value of \\
product \\
- Unit cost of feed \\
- Unit price of product \\
- Heating value of feed \\
- Heating value of \\
product \\
Fixed parameters, obtained \\
rom literatures.
\end{tabular} & \begin{tabular}{l}
\multicolumn{1}{c}{$\begin{array}{c}\text { Data } \\
\text { (Required) }\end{array}$} \\
- Feed quantity/flow rate \\
- Product quantity/flow \\
rate \\
- GHG emission \\
- GHG in feed \\
- Energy value of feed \\
- Energy value of product \\
- Economic value of feed \\
- Economic value of \\
product \\
- Power consumption by \\
process unit \\
- Power generation by \\
process unit \\
- Heat consumption by \\
process unit \\
Heat generation by \\
process unit
\end{tabular} \\
\hline
\end{tabular}

Fig. 2 - 3E assessment.

- Lever rule: A design option is said to be more favourable compared to the others if the relative distance from the base case is greater on the Production Feasibility Plot.

The Production Feasibility Plot provides a clearer visualisation of the economic and technical performances of each design option through the position and relative distance, compared to examination by means of numerical values. In Fig. 3, Case 0 is the reference case while Cases 1 and 2 are new design options. According to the up-right rule and lever rule, Case 1 is preferred over Case 2 because it has shifted to an upright position with respect to Case 0 , falls in zone $\mathrm{A}$-feasible and favourable region and that the relative distance of Case 1 is further away from Case 0 compared to Case 2 from Case 0 . It should be noted that variation in product and/or feed price may result in a potentially favourable option to be located in zone B instead of zone A. Therefore, up-right rule should be applied for comparing various design options, rather than justifying merely based on the zones. This will become more evident for the case studies demonstrated in Section 3.2.

Apart from economic and energy aspects, environmental impact due to greenhouse gas (GHG) emissions, such as $\mathrm{CO}_{2}$ and $\mathrm{CH}_{4}$, should also be analysed. The analysis is performed by taking into account the total GHG emitted from the process to outside the system boundary with respect to the combined energy value of products, shown in Eq. (3). In a stricter evaluation, GHG should be assessed independently based on different products, rather than combining the total energy values of various products. This issue will be addressed in the subsequent analysis.

GHG emission $=\frac{\text { Total GHG emitted }}{\text { Total energy value of products }}$ 

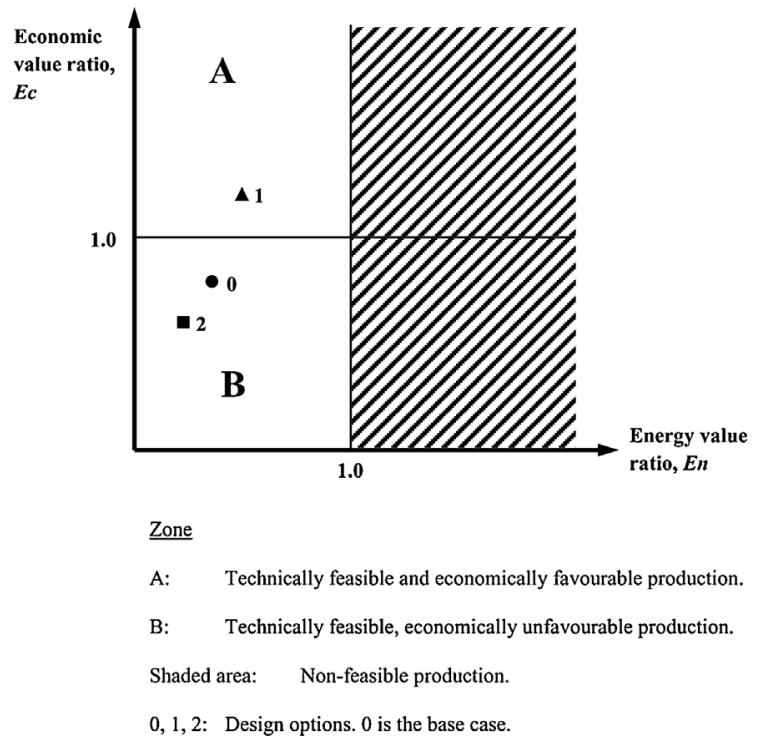

Fig. 3 - Production Feasibility Plot

\subsubsection{Inside boundary (IB) analysis}

Inside boundary (IB) analysis implies a more detailed examination of the individual process units that falls within the boundary of study. This way, the energy used/generated, GHG emitted/generated associated with each process, product and feed can be fully explored. IB analysis aims to quantify the performance of each design option and consequently justify the most preferred option. In IB analysis, the performance indicators embrace three major aspects: process energy intensity, process GHG intensity and process recoverable energy.

2.2.3.1. Process energy intensity. In $\mathrm{OB}$ analysis, energy value ratio is used to quantify the performance of a design option (Eq. (2)). This only considers the initial and final energy states, without emphasising on the process itself. The evaluation of net energy demand of a process, $E D_{i}^{\text {net }}$ is required in IB analysis, shown in Eq. (4). In contrast to energy efficiency, process energy intensity, EI defined in Eq. (5) is the net energy demand per unit energy value of product, relating energy demand to the production. The energy under consideration can be in the forms of heat (if steam is used/generated) or power (if electricity is used/generated), however they should be assessed independently and should not be aggregated. For analysing polygeneration systems, EI is a better indication compared to energy efficiency because the energy used in each production route can be examined, which is one of the main objectives of performing IB analysis.

$\mathrm{ED}_{i}^{\text {net }}=\mathrm{ED}_{\mathrm{i}}-\mathrm{EG}_{\mathrm{i}}$

$\mathrm{EI}=\sum_{i=1}^{n} \frac{\mathrm{ED}_{i}^{\text {net }}}{E \mathrm{p}_{i}}$

where $E D_{i}^{\text {net }}$ is the net energy (heat/power) demand of process $i, \mathrm{MW} ; \mathrm{ED}_{i}$ is the energy (heat/power) demand of process i, MW; $E_{i}$ is the energy (heat/power) generation from process $i, M W$; EI is the process energy (heat/power) intensity, MW/MW product $\mathrm{Ep}_{\mathrm{i}}$ is the energy value of product in process $i, \mathrm{MW} ; n$ is the total number of processes.

2.2.3.2. Process GHG intensity. With regard to environmental impact, $\mathrm{OB}$ analysis considers the total GHG emitted from the system with reference to the total energy value of product (Eq. (3)). From OB analysis, there is no evidence of which process or production route releases more GHG compared to the others. IB analysis aims to examine into the details of the processes in order to understand which production route has higher tendency in generating GHG. The net generation of GHG, GHG ${ }_{i}^{\text {gen,net }}$ can be determined using Eq. (6) which signifies the balance of GHG component originally presence in the feed and the GHG component emitted to the atmosphere. In the present context, the boundary of the system is the process itself and not the external environment. Hence, mass balance is conducted around the process which generates or emits GHG. It should not be confused with the concept of calculating carbon footprint of the environment. GHG intensity, GHGI is adopted to measure the net generation of GHG per unit energy value of product, shown in Eq. (7).

$$
\begin{aligned}
& \mathrm{GHG}_{i}^{\text {gen,net }}=\mathrm{GHG}_{i}^{\text {emi }}-\mathrm{GHG}_{i}^{\text {feed }} \\
& \mathrm{GHGI}=\sum_{i=1}^{n} \frac{\mathrm{GHG}_{i}^{\text {gen,net }}}{\mathrm{Ep}_{i}}
\end{aligned}
$$

where $\mathrm{GHG}_{i}^{\text {gen,net }}$ is the net GHG generation of process $i, \mathrm{t} / \mathrm{h}$; $\mathrm{GHG}_{i}^{\mathrm{emi}}$ is the GHG emission from process $i, \mathrm{t} / \mathrm{h}$; $\mathrm{GHG}_{i}^{\text {feed }}$ is the GHG in feed of process $i, \mathrm{t} / \mathrm{h}$; GHGI is the process GHG intensity, $\mathrm{t} / \mathrm{MWh}$ or $\mathrm{kg} / \mathrm{MJ}$.

2.2.3.3. Process recoverable energy. There could be some opportunities in recovering certain parts of the energy in the form of heat from the process units or streams during cooling or where exothermic reaction takes place. In general, only high temperature level and/or high heat duties streams or process units should be extracted for the analysis. $\mathrm{Ng}$ et al. (2010) provided the details of data extraction and heuristics apropos energy integration. The process recoverable energy should be differentiated from the energy generation examined in process energy intensity. This is the inherent potential recoverable heat that is not annotated on the process flow diagram as energy generation and it is the result from further energy integration investigation. If the process flow diagram shows the process of generating steam from water, then this should be accounted in process energy intensity instead of process recoverable energy because steam is considered as the product. The process recoverable energy, ER is defined in Eq. (8) as the total energy (heat) released from process due to exothermic reaction per unit energy value of feed. It should be noted that energy value of feed instead of product is taken as the basis. This is for the sake of avoiding ER of greater than 1.0 because there might be instances where the recoverable energy is greater than the energy value of product. In addition, it is more sensible to treat the recoverable energy as the remaining energy from the feed and thus only ER values of less than 1.0 can be obtained.

$\mathrm{ER}=\sum_{i=1}^{n} \frac{\mathrm{H}_{\mathrm{i}}}{\mathrm{Ef}_{\mathrm{i}}}$

where ER is the process recoverable energy (heat) ratio, $H_{\mathrm{i}}$ is the total energy (heat) released from process $i$ due to exothermic reaction, $\mathrm{MW} ; \mathrm{Ef}_{\mathrm{i}}$ is the energy value of feed in process $\mathrm{i}, \mathrm{MW}$.

2.2.3.4. Economic analysis using scale factor method. In $\mathrm{OB}$ analysis, it is the feed-to-product economic efficiency (Eq. (1)) 
that has been measured. However, it does not reflect the economic investment involved in each design option, such as the capital and operating costs. The order of preference of design option might be different after taking into consideration the costs involved inside the system boundary. It is often desirable to avoid extraneous and detailed economic evaluation such as installation cost of equipment, fixed operating cost etc., extensive literature search on the cost data and also using additional software such as Aspen Icarus which is widely used in industry for economic evaluation. Therefore, economic analysis using scale factor method is proposed in this study to examine the economic impact of the design options relative to the base case. The advantage of this approach is that only information available directly from process modelling and $\mathrm{OB}$ analysis is required in carrying out the analysis (Fig. 2). In other words, economic evaluation using absolute cost is not needed in the present analysis and comparison is done via examining the economic impact of various design options which is merely based on the relative cost with respect to the base case. Note: The modification would involve duplication of process units in different design options, instead of using different types of process units.

Step 1: Select a base case for like-to-like comparison. The cost of the base case will serve as the reference point to determine the relative cost of other cases as shown in Step 2. The base case system should have the complete set of process units.

Step 2: Since the costs of all equipment for the design option that involves the complete set of process units (base case) is considered as the reference costs, the base $\operatorname{cost} C_{1}$ of each item of equipment is set to unity. The cost of other design options is then calculated relative to the base case. This suggests that the cost of the same set of process unit from other design options is estimated in terms of factor with respect to the value of 1 . The relative capital cost for the process unit is estimated using Eq. (9), where only the capacities of process units are required. The total relative capital costs of process units are summed up and normalised with respect to the base case.

$\frac{C_{2}}{C_{1}}=\left(\frac{S_{2}}{S_{1}}\right)^{R}$

where $C_{1}$ is the cost of the base unit. $C_{1}=1$ according to Step $1, C_{2}$ is the cost of the unit after scaling up/down, $S_{1}$ is the capacity of the base unit, $S_{2}$ is the capacity of the unit after scaling up/down, $R$ is the scaling factor. $R=0.6$ is assumed, i.e. six-tenth rule.

Step 3: A relative operating cost is also estimated. Only variable operating cost such as electricity and other utilities is accounted. The only information needed is the utility consumption and the unit price of this is not required. The total relative operating cost are summed up and normalised with respect to the base case.

Step 4: The relative capital and operating costs are summed up to obtain the total relative annualised cost and it is then normalised with respect to the base case.

2.2.3.5. 3E assessment. The 3E performance assessment consists of the following three components:

- Energy (process energy intensity, process energy recovery)

- Environment (GHG intensity)

- Economy (total annualised cost: capital and operating)
The three components should be coupled to one another to form a single metric so that it can be applied to quantify and compare the performance of various design options. The present study proposed that the energy and environment impacts should be translated into economic equivalent value so that these criteria can be easily understood since economy has always been the main driver for any project development in process industry. An economic "worthiness" term, $\Delta v_{p} / \Delta$ TAC, shown in Eq. (10a) is introduced, which is the ratio of relative value of product to relative total annualised cost, with respect to the base case. In any design modification, higher $\Delta v_{p} / \Delta \mathrm{TAC}$ value implies that the increase in value of product has outweighed the increase in total capital cost and hence it is economically worthwhile. Likewise, Eq. (10b) is defined as the economic worthiness with respect to feed.

$$
\begin{aligned}
{\left[\frac{\Delta v_{p}}{\Delta \mathrm{TAC}}\right]_{k, 0} } & =\frac{v_{p, k} / v_{p, 0}}{\mathrm{TAC}_{k} / \mathrm{TAC}_{0}}=\frac{q_{p, k} \times c_{p} / q_{p, 0} \times c_{p}}{\mathrm{TAC}_{k} / \mathrm{TAC}_{0}} \\
& =\frac{q_{p, k} / q_{p, 0}}{\text { Normalised } \mathrm{TAC}_{k, 0}} \\
{\left[\frac{\Delta v_{f}}{\Delta \mathrm{TAC}}\right]_{k, 0} } & =\frac{v_{f, k} / v_{f, 0}}{\mathrm{TAC}_{k} / \mathrm{TAC}_{0}}=\frac{q_{f, k} \times c_{f} / q_{f, 0} \times c_{f}}{\mathrm{TAC}_{k} / \mathrm{TAC}_{0}} \\
& =\frac{q_{f, k} / q_{f, 0}}{\text { Normalised } \mathrm{TAC}_{k, 0}}
\end{aligned}
$$

where $\Delta v_{p}$ is the relative value of product, $\Delta v_{f}$ is the relative value of feed, $\triangle \mathrm{TAC}$ is the relative total annualised cost, $v_{p, k}$ and $v_{p, 0}$ are the values of product for design option $k$ and base case, respectively, $v_{f, k}$ and $v_{f, 0}$ are the values of feed for design option $k$ and base case, respectively, $\mathrm{TAC}_{k}$ and $\mathrm{TAC}_{0}$ are the total annualised costs for design option $k$ and base case, respectively, $q_{p, k}$ and $q_{p, 0}$ are the quantities per unit time (flow rate/power) of product for design option $k$ and base case, respectively, $q_{f, k}$ and $q_{f, 0}$ are the quantities per unit time (flow rate/power) of feed for design option $k$ and base case, respectively, $c_{p}$ is the unit selling price of product. $c_{p, k}=c_{p, 0}, c_{f}$ is the unit cost of feed. $c_{f, k}=c_{f, 0}$.

The derivation of $3 \mathrm{E}$ index is demonstrated as follows:

Eq. (11a) signifies that the 3E index, $I_{3 E}^{\prime}$ is a function of process energy intensity (EI), process GHG intensity (GHGI) and process energy recovery (ER). However, $I_{3 E}^{\prime}$ has a nonunified dimension due to the combination of three different terms with mass and energy dimensions. Eq. (11b) shows the translation of $\mathrm{I}_{3 \mathrm{E}}^{\prime}$ into an index with economic implication, $\mathrm{I}_{3 \mathrm{E}}$ by introducing an economic worthiness term (Eqs. (10a) and $(10 b))$.

$I_{3 E}^{\prime}=f(E I, \quad G H G I, \quad E R)$

$I_{3 E}=I_{3 E}^{\prime} \times$ Economic worthiness $=f(E I$, GHGI, ER $)$

$\times$ Economic worthiness

Eqs. (11c)-(11e) show the conversions of energy and environment implications of components EI (Eq. (5)), GHGI (Eq. (7)) and ER (Eq. (8)) into a term which represents the economic implication of each aspect. EI and ER are dimensionless, while GHGI has the dimension of mass per unit energy. Eq. (11d) has included the lower heating value of product, $\mathrm{LHV}_{p}$ to eliminate the mass-energy dimension in GHGI. It should be noted that Eq. (11e) has adopted economic worthiness with respect to the feed (Eq. (10b)). This is because ER is estimated using 
value of feed as the basis in Eq. (8), and hence explained such convention.

Process Energy Intensity with economic implication

$$
=\mathrm{EI} \times \frac{\Delta v_{p}}{\Delta \mathrm{TAC}}
$$

Process GHG Intensity with economic implication

$$
=\mathrm{GHGI} \times \mathrm{LHV}_{p} \times \frac{\Delta v_{p}}{\Delta \mathrm{TAC}}
$$

Process Energy Recovery with economic implication

$$
=\mathrm{ER} \times \frac{\Delta v_{f}}{\Delta \mathrm{TAC}}
$$

By combining Eqs. (11c)-(11e) into Eq. (11b), I $3 E$ for single product system is expressed in Eq. (11f). Eq. (11g) shows the expression of $I_{3 E}$ for polygeneration system.

Single product system:

$$
\begin{aligned}
I_{3 E}= & {\left[\mathrm{EI} \times \frac{\Delta v_{p}}{\Delta \mathrm{TAC}}\right]+\left[\mathrm{GHGI} \times \mathrm{LHV}_{p} \times \frac{\Delta v_{p}}{\Delta \mathrm{TAC}}\right] } \\
& -\left[\mathrm{ER} \times \frac{\Delta v_{f}}{\Delta \mathrm{TAC}}\right]
\end{aligned}
$$

Multiple products (polygeneration) system:

$$
\begin{aligned}
\mathrm{I}_{3 \mathrm{E}}= & \sum_{i=1}^{n}\left[\mathrm{EI}_{i} \times\left(\frac{\Delta \mathrm{v}_{p}}{\Delta \mathrm{TAC}}\right)_{i}\right] \\
& +\sum_{i=1}^{n}\left[\mathrm{GHGI}_{i} \times \mathrm{LHV}_{p, i} \times\left(\frac{\Delta v_{p}}{\Delta \mathrm{TAC}}\right)_{i}\right] \\
& -\sum_{i=1}^{n}\left[\mathrm{ER}_{i} \times\left(\frac{\Delta v_{f}}{\Delta \mathrm{TAC}}\right)_{i}\right]
\end{aligned}
$$

$I_{3 E}$ provides a unified indicator showing the performance of a system in three aspects, i.e. process energy intensity, process GHG intensity and process energy recovery, shown in each term as the order in Eqs. (11f) and (11g). $I_{3 \mathrm{E}}$ is a dimensionless metric because the economic worthiness term is dimensionless, EI and ER measured on the basis of energy value are dimensionless, while GHGI is transformed to a dimensionless form by multiplying with the LHV of product. The performance is quantified using the economic equivalent value translated through multiplication of an economic "worthiness" term, i.e. $\Delta v_{p} / \Delta$ TAC or $\Delta v_{f} / \Delta$ TAC. The economic worthiness with respect to value of product $\left(\Delta v_{p} / \Delta \mathrm{TAC}\right)$ gives an implication whether the changes in value of product resulting from the modification is able to justify the corresponding changes in TAC, i.e. higher $\Delta v_{p} / \Delta T A C$ suggests a significant improvement in the value of product or feed with minimal increase in TAC is desirable. Likewise, $\Delta v_{f} / \Delta$ TAC shows the sensitivity of the changes in the values of feed towards the changes in TAC.

Higher EI and GHGI are not desirable while higher ER is desirable. Therefore, the first two terms in Eqs. (11f) and (11g) signify the negative impacts while the third term implies the positive impact within the present context of performance criteria and hence the convention of plus and minus signs adopted here. Lower $\mathrm{EI} \times\left(\Delta v_{p} / \Delta \mathrm{TAC}\right)$ is desirable since it implies that the economic value-to-investment placed on energy intensity is less significant. Lower GHGI $\times \operatorname{LHV}_{p} \times$ $\left(\Delta v_{p} / \Delta \mathrm{TAC}\right)$ is desirable since it implies that the economic value-to-investment placed on GHG intensity is less significant. Higher $\mathrm{ER} \times\left(\Delta v_{f} / \Delta \mathrm{TAC}\right)$ is desirable since it implies that the economic value-to-investment can be recovered through energy recovery. Hence, Eqs. (11f) and (11g) also implies that $I_{3 E}$ should be as low as possible compared to the base case for a favourable and sustainable design.

$I_{3 E}$ is a metric used to justify the performance of various design options relative to the base case. It is rather a relative value and not an absolute value indicating the performance of a particular design. This is mainly attributed to the shortcut method applied in the economic analysis using scale factor method that has adopted the values relative to the base case. However, it does not affect the results of the analysis and it is sufficiently capable to be applied for comparison purposes.

\section{Case Study and analysis of polygeneration systems}

In the present study, integrated gasification systems with various production routes and configurations have been analysed using the proposed framework for 3E assessment. Gasification process converts feedstock such as coal and biomass into syngas which contains carbon monoxide and hydrogen as the major components. Attributed to these components, syngas is potentially a very useful building block in synthesising many types of fuels, chemicals and power, and thus highly capable and suitable for polygeneration. Syngas needs to be cleaned and conditioned to meet the requirement for any synthesis processes. Favourably, $\mathrm{CO}_{2}$ contained in the syngas is removed for pollution prevention purposes, either before or after the synthesis process. A block flow diagram showing an integrated gasification system is illustrated in Fig. 4(a). Detailed description and modelling of the system can be found elsewhere (Ng et al., 2013).

The proposed conceptual design approach shown earlier in Fig. 1 and Section 2 is demonstrated in the following sections, comprising of scope definition (Section 3.1) and 3E assessment (Section 3.2). The design objective is to determine which production route or configuration would result in the best performance in energy, economic and environmental aspects. Investigation on different process technologies will not be conducted. It is assumed that there is no specific production target and that the feed flowrate is fixed. For the sake of simplicity in demonstrating the methodology and meeting the criterion for polygeneration, the objective is set to synthesising a maximum of two products, which excludes heat (heat is regarded as recoverable energy). Methanol and electricity have been selected as the desired products in the present study.

\subsection{Scope definition}

Scope definition in the proposed methodology includes defining the boundary of study and deriving design options, discussed in Sections 3.1.1 and 3.1.2, respectively.

\subsubsection{Defining boundary of study}

Since the current focus is on the production route, it is rather straightforward to conclude in this case that the boundary of study falls within the product synthesis section (Fig. 4(a)). The evidence for selecting this boundary can be found in a study by Ng et al. (2012). The study investigated various coal 


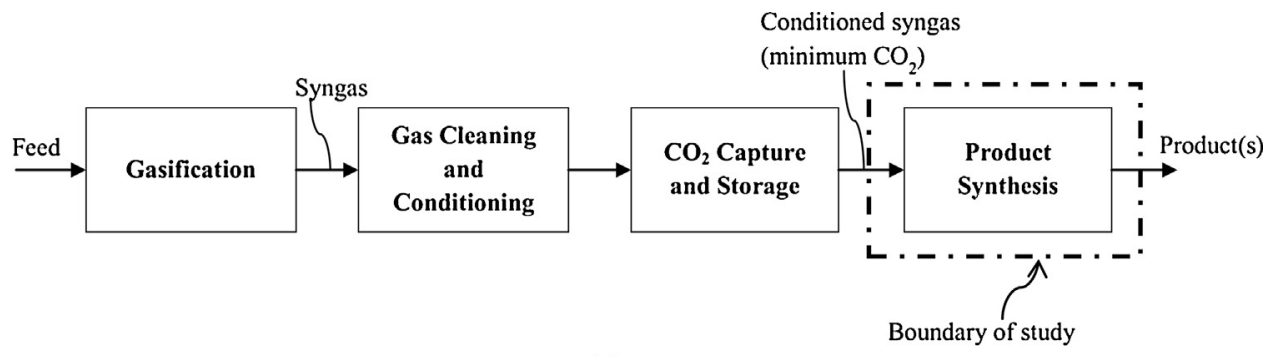

(a)

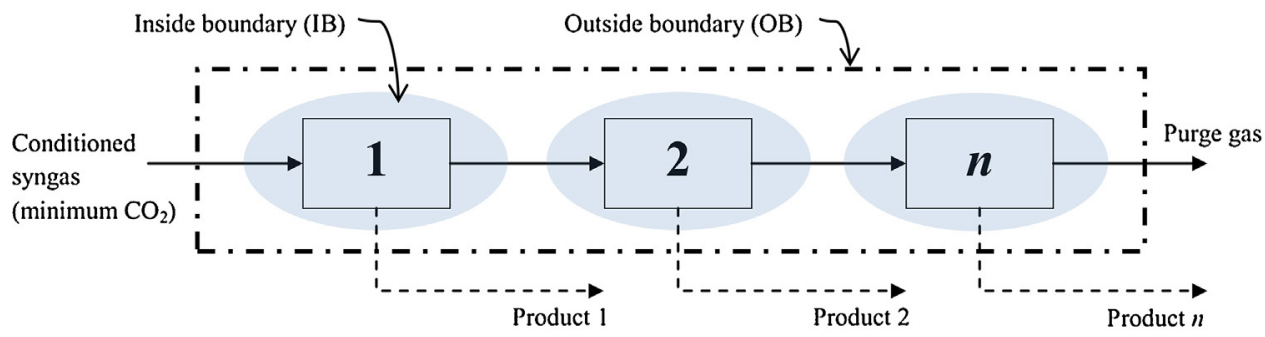

(b)

Fig. 4 - (a) Block flow diagram of typical integrated gasification system, where product synthesis section is defined as the boundary of study; (b) definition of outside and inside boundaries of the product synthesis section.

polygeneration system integrated with different decarbonisation options using block and boundary concept for design prioritisation and scoping analysis among similar type of systems with different production routes and configurations. Gasification, gas cleaning and conditioning sections can be separated from further analysis due to the similarity in energy and economic performances.

Fig. 4(b) shows the product synthesis section together with the definition of outside and inside boundaries of the system. The product synthesis section is analysed as a whole in the outside boundary analysis, while the individual processes within the system boundary are analysed in the inside boundary analysis. Defining the system boundary is an important step in the current framework because the subsequent $3 \mathrm{E}$ assessment will be performed using the stream and process information that is confined within the defined boundary. The derivation of design options is then carried out with a focus on the selected boundary of study-the product synthesis section.

\subsubsection{Derivation of design options}

As a fundamental principle, for any modification on the existing design or creating a new design, it is always preferred to begin the evaluation from the simplest possible configuration (potentially the low-cost modification) and then gradually adding in new process unit (i.e. moderate-cost or high-cost modification). In view of the present objective that production target can be relaxed, this also implies that flexible degree of modification can be realised on the product synthesis section. The possible configurations are once-through or recycle, series or parallel and also parallel-series configurations, from single product to multiple products generation. Such principle will be adopted for deriving the design options in this case. There are 8 main configurations in total, illustrated in Fig. 5 (single production system-Base Case and Case 1), Fig. 6 (polygeneration, series production system-Case 2 and Case 3), Fig. 7 (polygeneration, parallel production system-Case 4 and Case 5) and Fig. 8 (polygeneration, parallel-series production system-Case 6 and Case 7). In addition to this, some cases that consist of degree of freedom such as the split ratio of offgas into recycle stream and split ratio of syngas feed into the respective processes have also been studied, i.e. Cases 3 to 7.

For better visualisation on the modification in configuration, a simplified block diagram alongside with an Aspen Plus model are provided in each case. It should be noted that purge gas and exhaust gas are fundamentally considered as waste gases that emit to the atmosphere. The difference between these two is that purge gas is normally released from recycle stream or a normal chemical synthesis process. Exhaust gas refers to the waste gas resulting from combustion process. Hence, these two types of gases differ in composition and heating values. In most cases, purge gas carries higher heating value than exhaust gas because it contains majority of carbon monoxide and hydrogen, while exhaust gas contains negligible carbon monoxide and hydrogen (subject to full combustion) but with significant amount of carbon dioxide. This explains the rationale of considering purge gas to be fed into other synthesis processes, while exhaust gas is not (unless $\mathrm{CO}_{2}$ reuse is considered).

The design options shown in Figs. 5-8 have been evaluated using the proposed $3 \mathrm{E}$ assessment, demonstrated in Section 3.2.

\section{2. $3 \mathrm{E}$ assessment}

The 8 major cases derived in Section 3.1.2 have been analysed using the systematic methodology elucidated in Sections 2.2.1 to 2.2.3, consisting of process modelling (Section 3.2.1), outside boundary analysis (Section 3.2.2) and inside boundary analysis (Section 3.2.3).

\subsubsection{Process modelling}

The product synthesis section shown in Fig. 4(a) has been modelled using Aspen Plus process simulation software, illustrated in Figs. 5-8. The Aspen Plus model specification used for modelling various configurations of the product synthesis section is provided in Table 1. For Case 1, 90\% recycle of offgas and 10\% purge are assumed. For Cases 3-7, the variation in offgas/syngas split ratio has also been studied for $90 \%, 50 \%$ and $10 \%$ with respect to the split to Process 1 , 


\section{Case 0 (Base Case)}
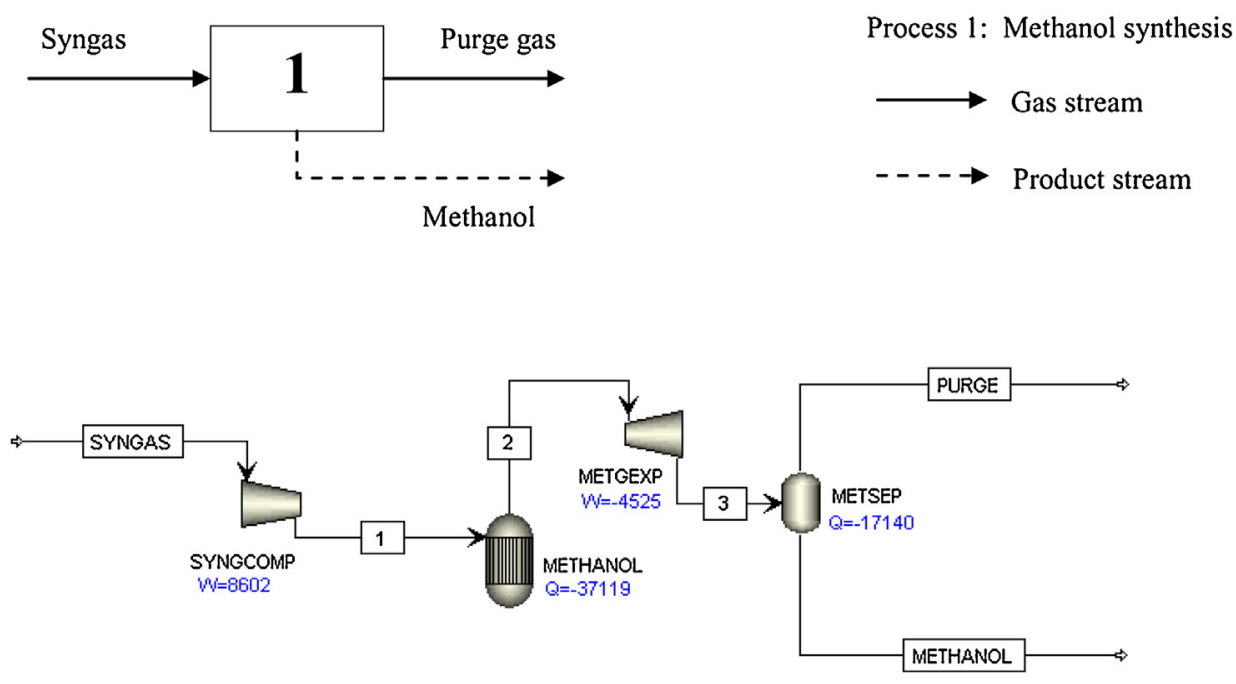

(a)

\section{Case 1}

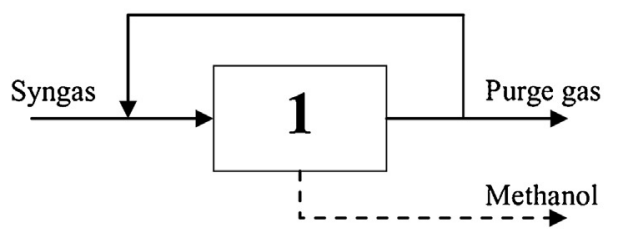

Process 1: Methanol synthesis
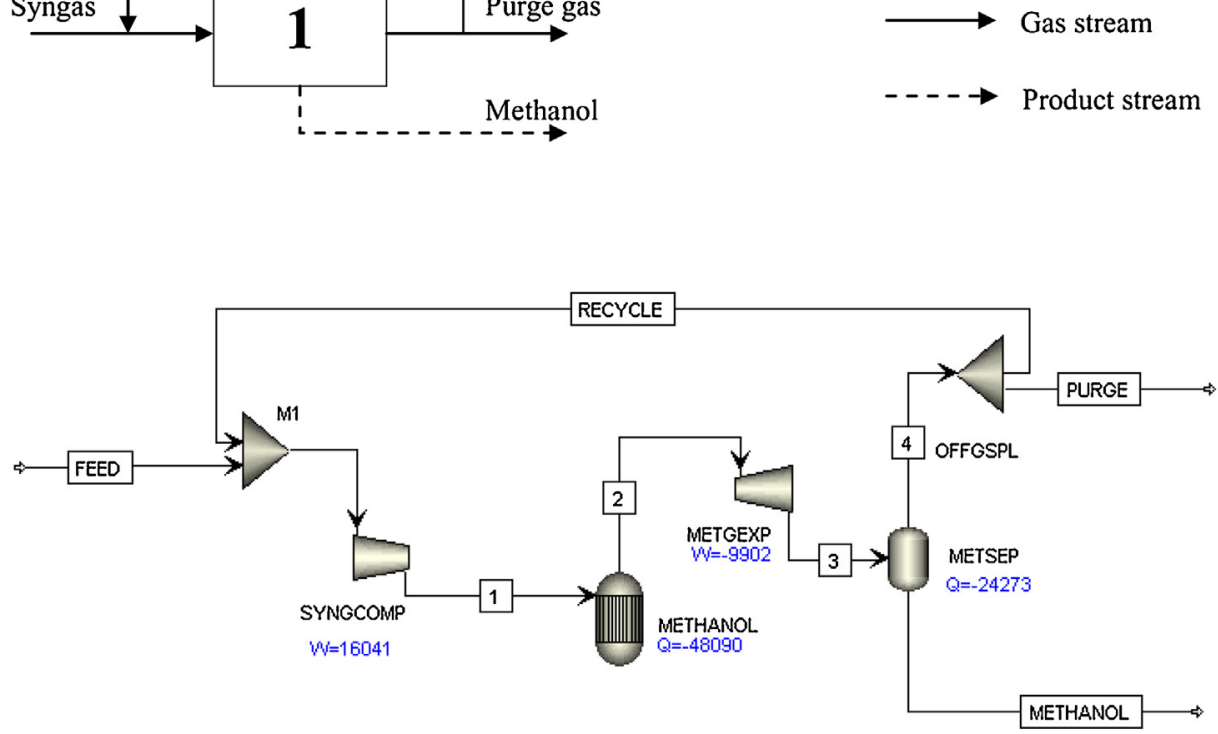

(b)

Fig. 5 - Single production system-methanol synthesis. (a) Case 0/Base case: once-through configuration; (b) Case 1: recycle configuration. (Top: simplified block flow diagram; Bottom: Aspen Plus modelling). (SYNGCOMP: Syngas compressor; METGEXP: Offgas expander; METHANOL: Methanol synthesis reactor; METSEP: Flash separator; M1: Feed and recycle mixer; OFFGSPL: Offgas splitter).

demonstrated in (a)-(c), respectively in each sub-case. When recycle configuration is considered in Cases $4-7,90 \%$ recycle of offgas is assumed.

\subsubsection{Outside boundary $(\mathrm{OB})$ analysis}

OB analysis, discussed in Section 2.2.2 has been carried out to analyse the energy and economic performances as well as
GHG impact. In the present case study, $\mathrm{CO}_{2}$ is the only GHG involved in the system (methane content is negligible).

An illustrative example of $O B$ analysis for the polygeneration system (series configuration) in Case 2 is shown as follows, where Eqs. (1)-(3) in section 2.2.2 have been applied.

$$
\begin{gathered}
\text { Economic value ratio, } E c=\frac{\text { Economic value of products (methanol electricity) }}{\text { Economic value of feed (syngas) }} \\
=\frac{(144.7+18.9) \mathrm{M} € / \mathrm{y}}{184.7 \mathrm{M} € / \mathrm{y}}=0.89
\end{gathered}
$$


Case 2
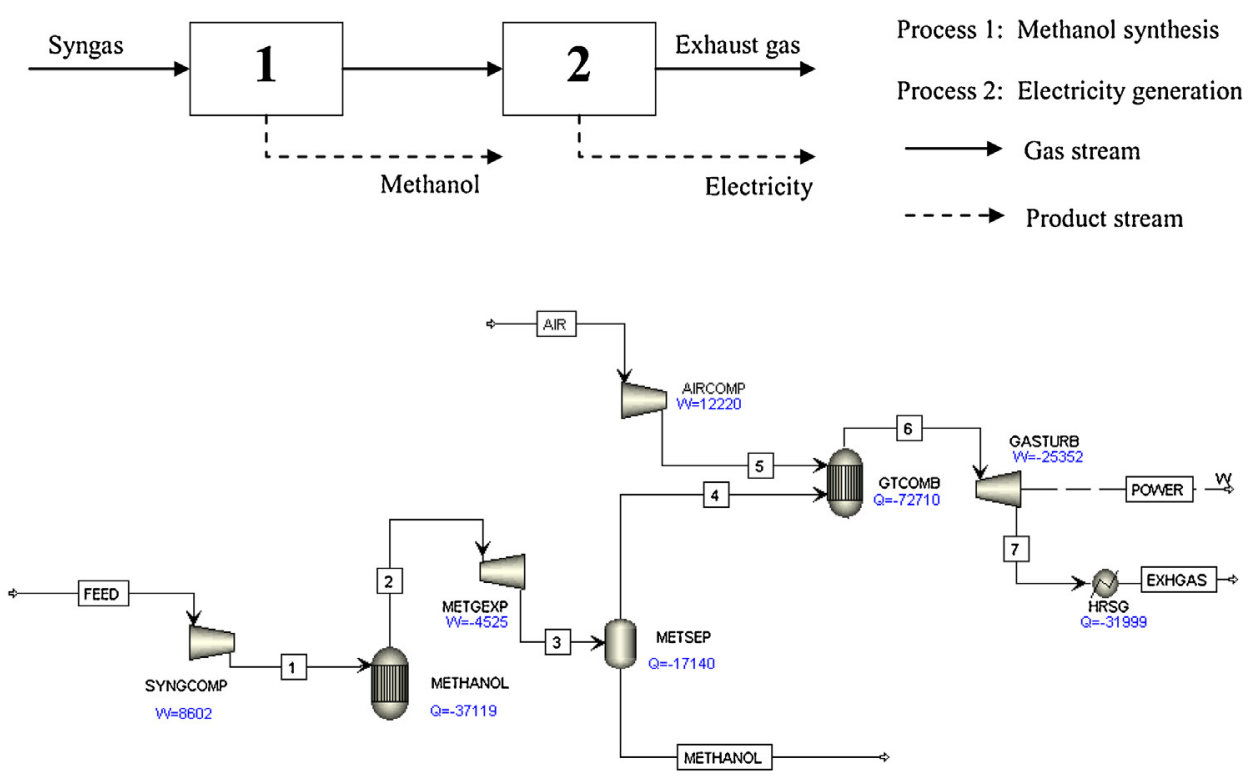

(a)
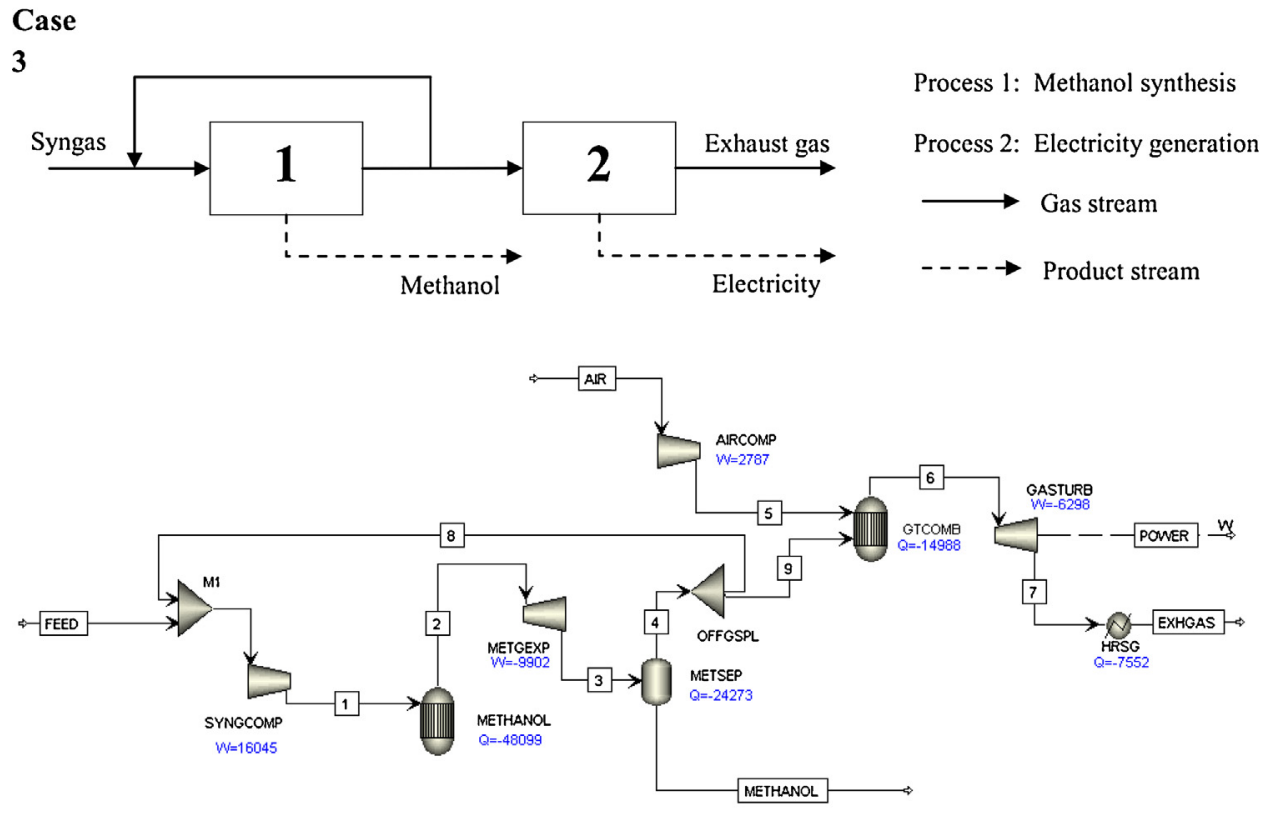

(b)

Fig. 6 - Series production system-methanol synthesis and electricity generation. (a) Case 2: once-through configuration; (b) Case 3: recycle configuration. (Top: simplified block flow diagram; Bottom: Aspen Plus modelling). (SYNGCOMP: Syngas compressor; METGEXP: Offgas expander; METHANOL: Methanol synthesis reactor; METSEP: Flash separator; M1: Feed and recycle mixer; OFFGSPL: Offgas splitter; AIRCOMP: Air compressor; GTCOMB: Gas turbine combustion chamber; GASTURB: Gas turbine; HRSG: Heat recovery steam generator).

Energy value ratio, $E n=\frac{\text { Energy value of products (methanol }+ \text { electricity) }}{\text { Energy value of feed (syngas) }}$

$$
=\frac{(245.1+25.4) \mathrm{MW}}{420.2 \mathrm{MW}}=0.64
$$

$\mathrm{CO}_{2}$ emission $=\frac{\text { Total } \mathrm{CO}_{2} \text { emitted }}{\text { Total energy value of products (methanol }+ \text { electricity) }}$

$$
\begin{aligned}
& =\frac{23.16 \mathrm{t} / \mathrm{h}}{(245.1+25.4) \mathrm{MW}} \times \frac{1000 \mathrm{~kg} / \mathrm{t}}{3600 \mathrm{MJ} / \mathrm{MWh}} \\
& =0.024 \mathrm{~kg} / \mathrm{MJ} \text { product }
\end{aligned}
$$


Case 4
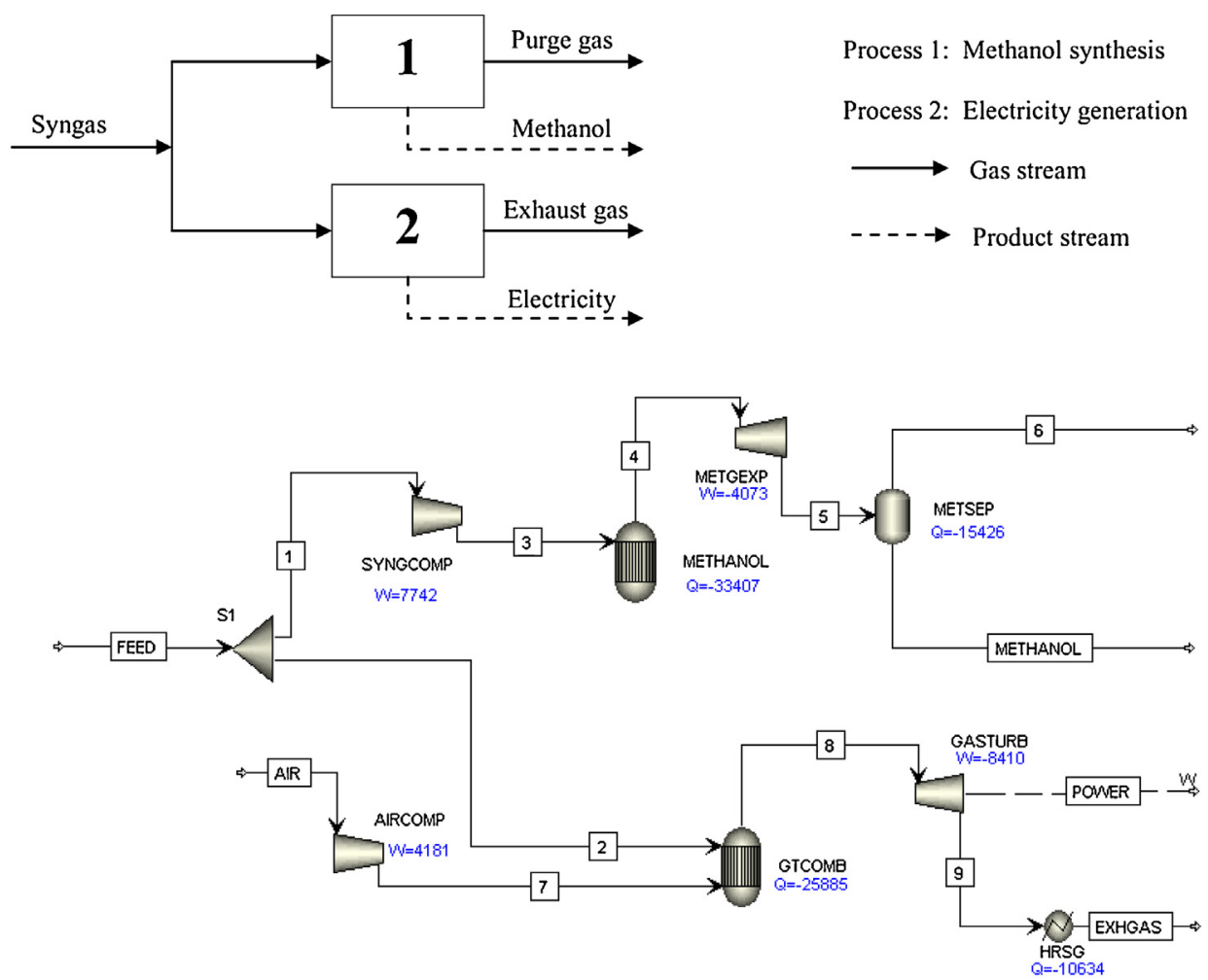

Case 5

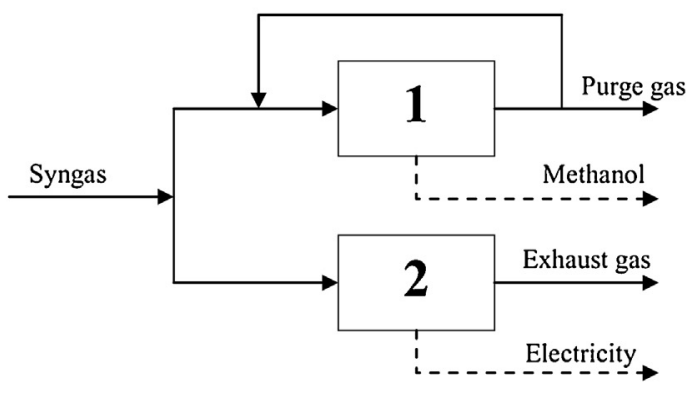

Process 1: Methanol synthesis

Process 2: Electricity generation

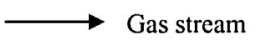

$--\rightarrow$ Product stream

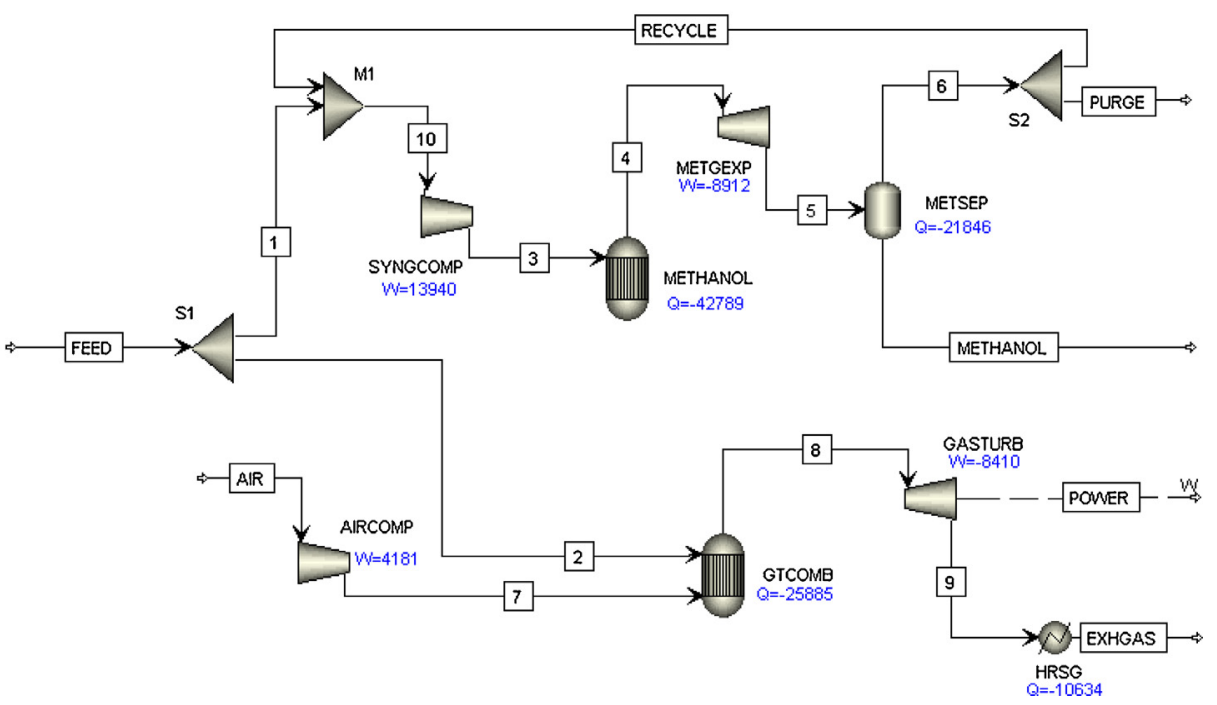

Fig. 7 - Parallel production system-methanol synthesis and electricity generation. (a) Case 4: once-through configuration; (b) Case 5: recycle configuration. (Top: simplified block flow diagram; Bottom: Aspen Plus modelling). (SYNGCOMP: Syngas compressor; METGEXP: Offgas expander; METHANOL: Methanol synthesis reactor; METSEP: Flash separator; M1: Feed and recycle mixer; S1: Syngas feed splitter; S2: Offgas splitter; AIRCOMP: Air compressor; GTCOMB: Gas turbine combustion chamber; GASTURB: Gas turbine; HRSG: Heat recovery steam generator). 
Case 6

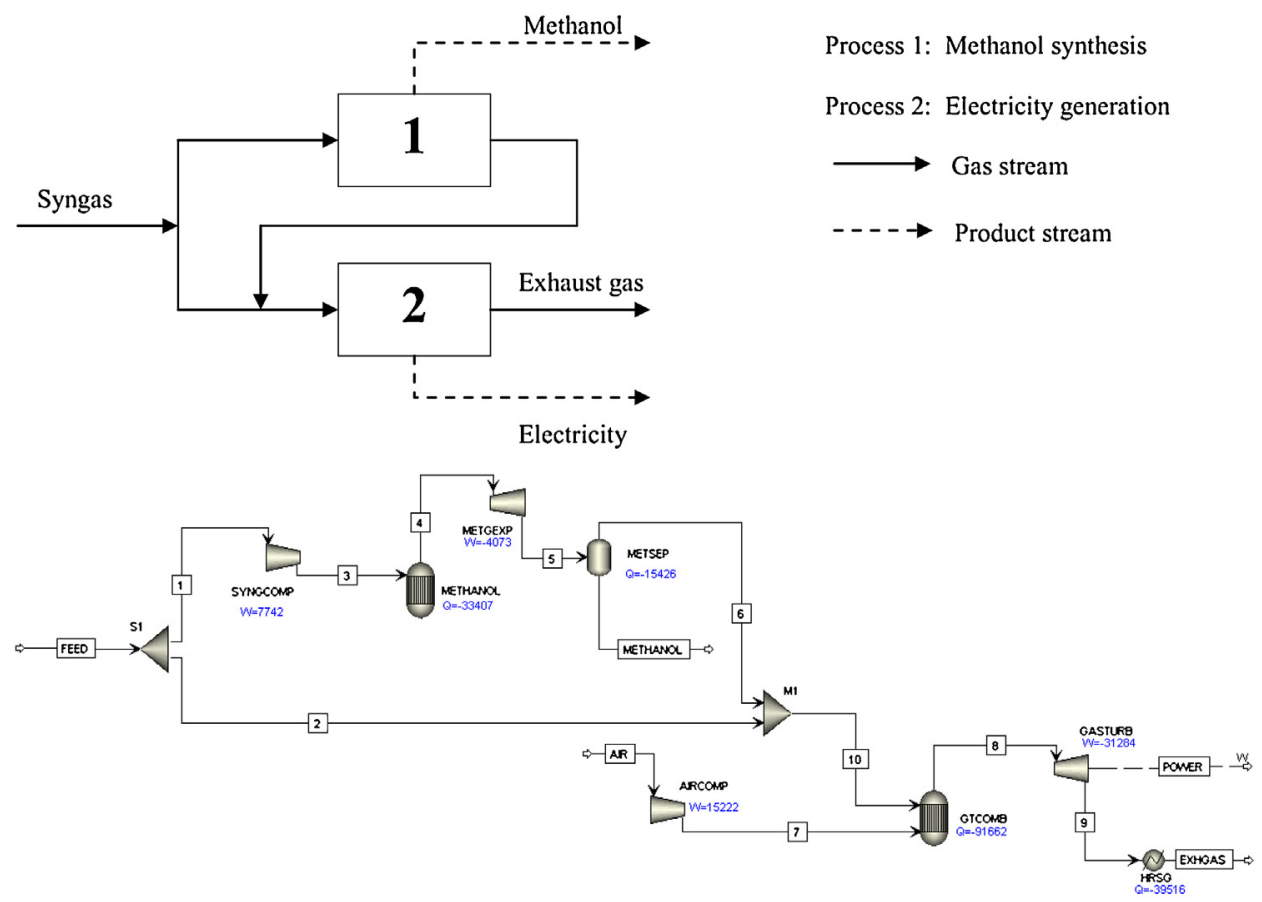

Case 7

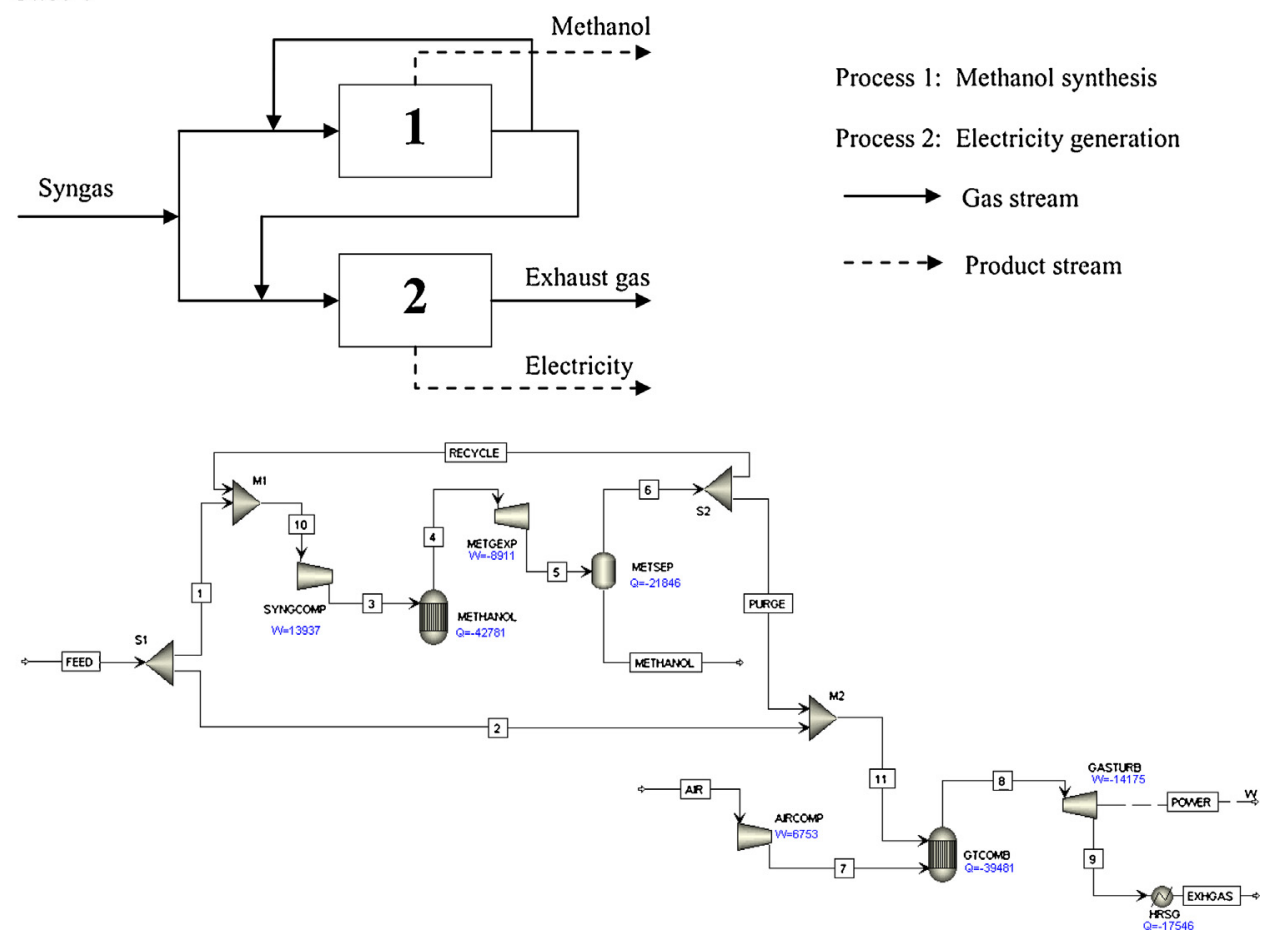

Fig. 8 - Parallel-series production system-methanol synthesis and electricity generation. (a) Case 6: once-through configuration; (b) Case 7: recycle configuration. (Top: simplified block flow diagram; Bottom: Aspen Plus modelling). (SYNGCOMP: Syngas compressor; METGEXP: Offgas expander; METHANOL: Methanol synthesis reactor; METSEP: Flash separator; M1: Feed and recycle mixer; M2: Purge and syngas feed mixer; S1: Syngas feed splitter; S2: Offgas splitter; AIRCOMP: Air compressor; GTCOMB: Gas turbine combustion chamber; GASTURB: Gas turbine; HRSG: Heat recovery steam generator).

A summary of results from $\mathrm{OB}$ analysis for each case is presented in Table 2.

The unit costs of electricity $(7.764$ pence/kWh or $€ 0.0259 / \mathrm{MWh}$ ) (DECC, Department of Energy and Climate Change (DECC), 2014) and methanol ( $€ 412$ per tonne or $€ 0.0205$ per MJ) can be obtained conveniently from opensource websites or reports (Methanex, 2014). Literature (Li et al., 2010) estimated the cost of production of syngas to be $\$ 0.056$ per $\mathrm{m}^{3}$, generated from coal at unit price of $\$ 40$ per tonne. Hence, the unit of syngas which is levelised by 4 times due to higher unit coal price of $£ 92.8$ per tonne (DECC, Department of Energy and Climate Change (DECC), 2014) in the $\mathrm{UK}$ is considered. The lower heating value of syngas is taken to be $22.02 \mathrm{MJ} / \mathrm{kg}$ or $10.3 \mathrm{MJ} / \mathrm{m}^{3}$, and methanol is $20.1 \mathrm{MJ} / \mathrm{kg}$. USD to Euro currency conversion is assumed to be 0.7 while GBP to Euro is assumed to be 1.2. Fig. 9 shows the Production 


\begin{tabular}{|c|c|c|c|c|}
\hline Unit & $\begin{array}{l}\text { ASPEN Plus } \\
\text { model }\end{array}$ & $\begin{array}{c}\text { Outlet } \\
\text { temperature }\left({ }^{\circ} \mathrm{C}\right)\end{array}$ & $\begin{array}{l}\text { Pressure } \\
\text { (bar) }\end{array}$ & Other specification \\
\hline AIRCOMP & Compr & & 14 & Isentropic efficiency $=0.9$ \\
\hline GASTURB & Compr & & 2 & Isentropic efficiency $=0.9$ \\
\hline GTCOMB & REquil & 1200 & 14 & \\
\hline HRSG & Heater & 100 & 1 & \\
\hline M1 & Mixer & & & \\
\hline M2 & Mixer & & & \\
\hline METGEXP & Compr & & 24 & Isentropic efficiency $=0.9$ \\
\hline METHANOL & REquil & 250 & 100 & \\
\hline METSEP & Flash2 & 40 & 24 & \\
\hline OFFGSPL & FSplit & & & Split fraction is case dependent. Case $1=0.9$; Case $3=($ a) 0.9 (b) 0.5 (c) 0.1 \\
\hline S1 & FSplit & & & Split fraction is case dependent. (a) 0.9 (b) 0.5 (c) 0.1 \\
\hline S2 & FSplit & & & Split fraction $=0.9$ \\
\hline SYNGCOMP & Compr & & 100 & Isentropic efficiency $=0.9$ \\
\hline
\end{tabular}

Feasibility Plot (r.f. Fig. 3) for facilitating the comparison of energy and economic performances for each case. For clearer presentation of the results, Fig. 9(a)-(c) illustrate the series, parallel and parallel-series production systems, respectively. Fig. 9(d) presents the best case among each category of configurations for overall comparison purposes.

\subsubsection{Inside boundary (IB) analysis}

Table 3 presents the economic analysis based on scale factor method, of which the methodology has been discussed in Section 2.2.3. The objective is to estimate the relative total annualised cost (TAC) from the relative annual capital cost
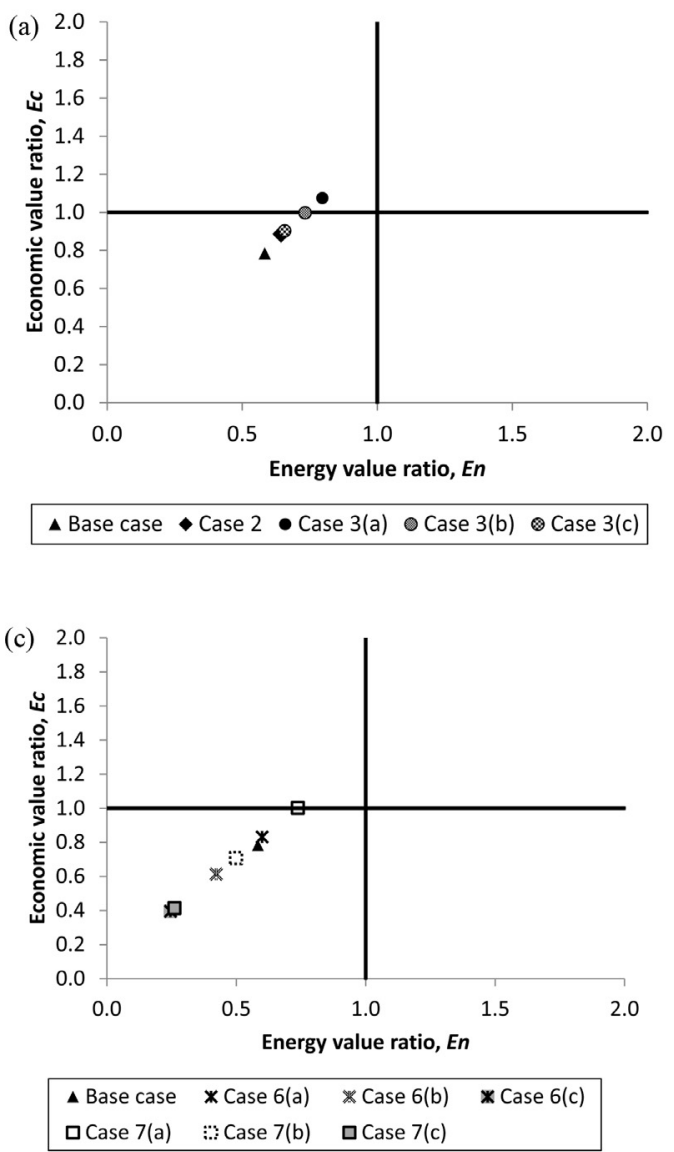

(ACC) and relative annual operating cost (AOC) and hence the economic worthiness $\left(\Delta v_{p} / \Delta \mathrm{TAC}\right.$ or $\left.\Delta v_{f} / \Delta \mathrm{TAC}\right)$. Table 3(a) provides the capacity information of equipment for the estimation of relative capital cost using Eq. (9), of which the results are shown in Table 3(b). Relative AOC is deduced from the electricity requirement of the system, presented in Table 3(c). TAC is obtained by summing ACC and AOC, shown in Table 3(d).

The economic worthiness is estimated using Eqs. (10a) and (10b), and the corresponding value of products and value of feed can be found in Table 2. An illustrative example of evaluating the economic worthiness for the polygeneration system (series configuration) in Case 2 is shown as follows.
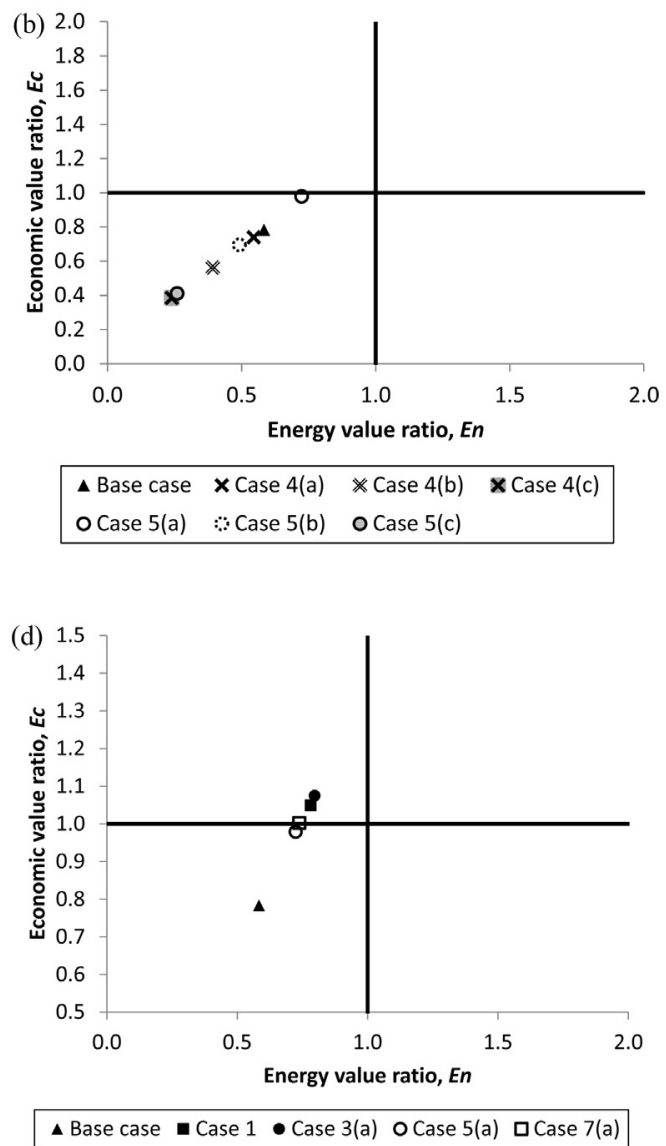

Fig. 9 - Production Feasibility Plot for various production systems (a) series production; (b) parallel production; (c) parallel-series production; (d) best cases from each category of production systems. 


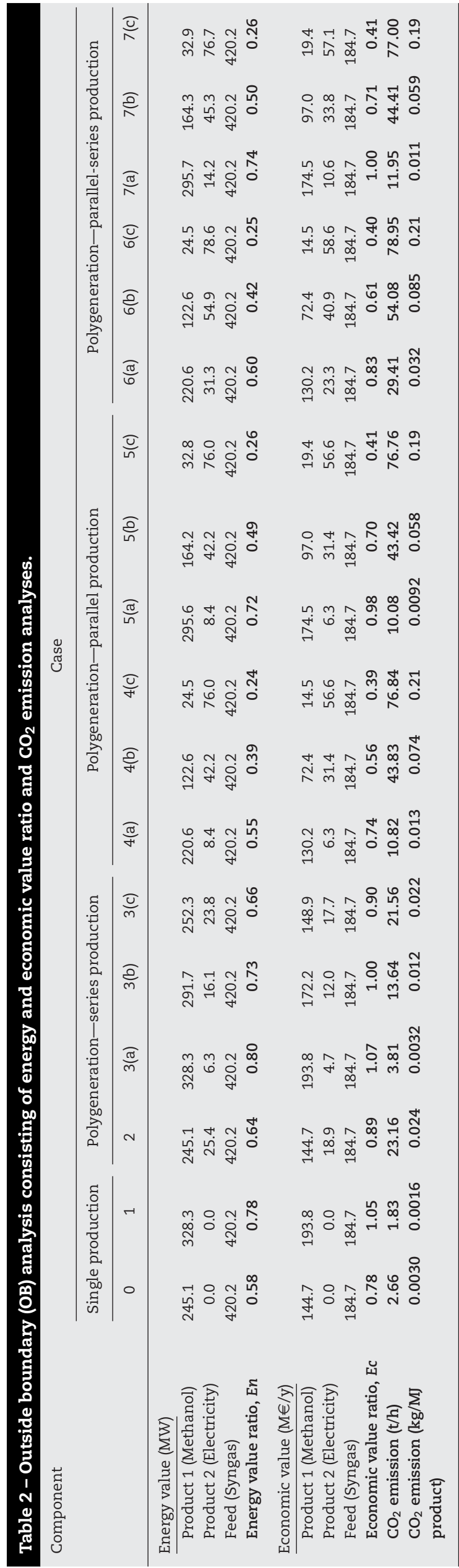

For methanol synthesis process (Process 1),

$$
\left[\frac{\Delta v_{p}}{\Delta \mathrm{TAC}}\right]_{k, 0}=\frac{q_{p, k} / q_{p, 0}}{\text { Normalised } \mathrm{TAC}_{k, 0}}=\frac{245.1 \mathrm{MW} / 245.1 \mathrm{MW}}{1}=1
$$

Similarly, for electricity generation process (Process 2),

$$
\left[\frac{\Delta v_{p}}{\Delta \mathrm{TAC}}\right]_{k, 0}=\frac{q_{p, k} / q_{p, 0}}{\text { Normalised } \mathrm{TAC}_{k, 0}}=\frac{25.4 \mathrm{MW} / 25.4 \mathrm{MW}}{1}=1
$$

Note that in this case, $k=0$ since Case 2 is the base case for examining polygeneration cases so that comparison on a liketo-like basis can be performed. Case 2 comprises of a complete set of equipment that is essential for carrying out economic analysis using scale factor method (r.f. Section 2.2.3).

An illustrative example of IB analysis for the polygeneration system (series configuration) in Case 2 is shown as follows, where Eqs. (11c)-(11e) have been applied.

For process energy intensity assessment in the current study, only the net power demand is required since the system involves the electricity required by syngas and air compression and offgas expansion, and no steam is required. The power requirement for syngas compressor and air compressor, and power generation from syngas expander can be obtained from Table 3(a). The power generation from gas turbine should not be taken into account in the process energy intensity assessment in light of the electricity generated from here is considered as the main product.

For methanol synthesis process (Process 1),

Process Energy Intensity with economic implication

$$
\begin{aligned}
& =\mathrm{EI} \times \frac{\Delta v_{p}}{\Delta \mathrm{TAC}} \\
& =\frac{\mathrm{ED}_{i}^{\text {net }}}{\mathrm{Ep}_{i}} \times \frac{\Delta u_{p}}{\Delta \mathrm{TAC}} \\
& =\frac{4.08 \mathrm{MW}}{245.11 \mathrm{MW}} \times 1 \\
& =0.017
\end{aligned}
$$

Similarly, for electricity generation process (Process 2), Process Energy Intensity with economic implication

$$
\begin{aligned}
& =\mathrm{EI} \times \frac{\Delta v_{p}}{\Delta \mathrm{TAC}} \\
& =\frac{E D_{i}^{\text {net }}}{\mathrm{Ep}_{\mathrm{i}}} \times \frac{\Delta v_{p}}{\Delta \mathrm{TAC}} \\
& =\frac{12.22 \mathrm{MW}}{25.35 \mathrm{MW}} \times 1 \\
& =0.482
\end{aligned}
$$

GHGI is to be multiplied by the LHV of product in order to yield a dimensionless metric. Electricity generally cannot be quantified using LHV. In this special case, Eq. (12) is used to estimate the so-called "LHV of electricity", where $\lambda$ is the conversion factor (MW electricity/MW feed). "LHV of electricity" in each case is different since $\lambda$ and $L_{H V}$ feed vary with different configuration. It is to be reminded that the feed refers to the stream that crosses the inside boundary of processes (i.e. stream entering gas turbine) and not the syngas that enters the outside boundary. $\mathrm{LHV}_{\text {feed }}$ can be estimated from 
Table 3 - Economic analysis based on scale factor method. (a) Capacity of equipment; (b) Relative annual capital cost estimation; (c) Relative annual operating cost estimation; (d) Summary of costs and economic worthiness. (a) Note: All capacities are given in the unit of MW, except for methanol synthesis reactor of which the unit of capacity is t/h.

(a)

\begin{tabular}{|c|c|c|c|c|c|c|c|c|c|c|c|c|c|c|c|c|c|c|c|}
\hline \multirow[t]{3}{*}{ Process } & \multirow[t]{3}{*}{ Component } & \multicolumn{18}{|c|}{ Case } \\
\hline & & \multicolumn{2}{|c|}{ Single production } & \multicolumn{4}{|c|}{ Polygeneration-series production } & \multicolumn{6}{|c|}{ Polygeneration-parallel production } & \multicolumn{6}{|c|}{ Polygeneration-parallel-series production } \\
\hline & & 0 & 1 & 2 & $3(a)$ & $3(b)$ & $3(c)$ & $4(\mathrm{a})$ & $4(b)$ & $4(\mathrm{c})$ & $5(a)$ & $5(b)$ & $5(c)$ & $6(\mathrm{a})$ & $6(b)$ & $6(c)$ & $7(\mathrm{a})$ & $7(b)$ & $7(c)$ \\
\hline \multirow[t]{3}{*}{1} & Syngas compressor & 8.60 & 16.04 & 8.60 & 16.05 & 10.72 & 9.20 & 7.74 & 4.30 & 0.86 & 13.94 & 7.74 & 1.55 & 7.74 & 4.30 & 0.86 & 13.94 & 7.74 & \\
\hline & $\begin{array}{l}\text { Methanol synthesis } \\
\text { reactor }\end{array}$ & 44.81 & 61.39 & 44.81 & 61.39 & 52.34 & 46.13 & 40.33 & 22.40 & 4.48 & 55.25 & 30.69 & 6.14 & 40.33 & 22.40 & 4.48 & 55.25 & 30.69 & \\
\hline & Offgas expander & 4.53 & 9.90 & 4.53 & 9.90 & 5.66 & 4.70 & 4.07 & 2.26 & 0.45 & 8.91 & 4.95 & 0.99 & 4.07 & 2.26 & 0.45 & 8.91 & 4.95 & 0.93 \\
\hline \multirow[t]{3}{*}{2} & Air compressor & 0.00 & 0.00 & 12.22 & 2.79 & 7.61 & 11.47 & 4.18 & 21.01 & 37.84 & 4.18 & 21.01 & 37.84 & 15.22 & 27.12 & 39.13 & 6.75 & 22.40 & 38 \\
\hline & Gas Turbine & 0.00 & 0.00 & 25.35 & 6.30 & 16.10 & 23.81 & 8.41 & 42.19 & 75.97 & 8.41 & 42.19 & 75.97 & 31.28 & 54.87 & 78.61 & 14.18 & 45.34 & \\
\hline & HRSG & 0.00 & 0.00 & 32.00 & 7.55 & 20.12 & 30.02 & 10.63 & 53.38 & 96.12 & 10.63 & 53.38 & 96.12 & 39.52 & 69.38 & 99.43 & 17.55 & 57.15 & 96.95 \\
\hline
\end{tabular}

(b)

\begin{tabular}{|c|c|c|c|c|c|c|c|c|c|c|c|c|c|c|c|c|c|c|c|}
\hline \multirow[t]{3}{*}{ Process } & \multirow[t]{3}{*}{ Component } & \multicolumn{18}{|c|}{ Case } \\
\hline & & \multicolumn{2}{|c|}{ Single production } & \multicolumn{4}{|c|}{ Polygeneration-series production } & \multicolumn{6}{|c|}{ Polygeneration-parallel production } & \multicolumn{6}{|c|}{ Polygeneration-parallel-series production } \\
\hline & & 0 & 1 & 2 & 3(a) & $3(b)$ & $3(c)$ & 4(a) & $4(b)$ & $4(c)$ & $5(\mathrm{a})$ & $5(b)$ & 5(c) & $6(\mathrm{a})$ & $6(\mathrm{~b})$ & $6(c)$ & $7(\mathrm{a})$ & $7(\mathrm{~b})$ & $7(\mathrm{c})$ \\
\hline \multirow[t]{5}{*}{1} & Syngas compressor & 1.00 & 1.45 & 1.00 & 1.45 & 1.14 & 1.04 & 0.94 & 0.66 & 0.25 & 1.34 & 0.94 & 0.36 & 0.94 & 0.66 & 0.25 & 1.34 & 0.94 & 0.36 \\
\hline & $\begin{array}{l}\text { Methanol synthesis } \\
\text { reactor }\end{array}$ & 1.00 & 1.21 & 1.00 & 1.21 & 1.10 & 1.02 & 0.94 & 0.66 & 0.25 & 1.13 & 0.80 & 0.30 & 0.94 & 0.66 & 0.25 & 1.13 & 0.80 & 0.30 \\
\hline & Offgas expander & 1.00 & 1.60 & 1.00 & 1.60 & 1.14 & 1.02 & 0.94 & 0.66 & 0.25 & 1.50 & 1.06 & 0.40 & 0.94 & 0.66 & 0.25 & 1.50 & 1.06 & 0.40 \\
\hline & Total & 3.00 & 4.26 & 3.00 & 4.26 & 3.38 & 3.08 & 2.82 & 1.98 & 0.75 & 3.97 & 2.79 & 1.06 & 2.82 & 1.98 & 0.75 & 3.97 & 2.79 & 1.06 \\
\hline & $\begin{array}{l}\text { Normalised annual } \\
\text { capital cost (ACC) }\end{array}$ & 1.00 & 1.42 & 1.00 & 1.42 & 1.13 & 1.03 & 0.94 & 0.66 & 0.25 & 1.32 & 0.93 & 0.35 & 0.94 & 0.66 & 0.25 & 1.32 & 0.93 & 0.35 \\
\hline \multirow[t]{5}{*}{2} & Air compressor & 0.00 & 0.00 & 1.00 & 0.41 & 0.75 & 0.96 & 0.53 & 1.38 & 1.97 & 0.53 & 1.38 & 1.97 & 1.14 & 1.61 & 2.01 & 0.70 & 1.44 & 1.98 \\
\hline & Gas Turbine & 0.00 & 0.00 & 1.00 & 0.43 & 0.76 & 0.96 & 0.52 & 1.36 & 1.93 & 0.52 & 1.36 & 1.93 & 1.13 & 1.59 & 1.97 & 0.71 & 1.42 & 1.94 \\
\hline & HRSG & 0.00 & 0.00 & 1.00 & 0.42 & 0.76 & 0.96 & 0.52 & 1.36 & 1.93 & 0.52 & 1.36 & 1.93 & 1.13 & 1.59 & 1.97 & 0.70 & 1.42 & 1.94 \\
\hline & Total & 0.00 & 0.00 & 3.00 & 1.27 & 2.27 & 2.89 & 1.56 & 4.10 & 5.84 & 1.56 & 4.10 & 5.84 & 3.41 & 4.79 & 5.96 & 2.10 & 4.27 & 5.87 \\
\hline & $\begin{array}{l}\text { Normalised annual } \\
\text { capital cost (ACC) }\end{array}$ & 0.00 & 0.00 & 1.00 & 0.42 & 0.76 & 0.96 & 0.52 & 1.37 & 1.95 & 0.52 & 1.37 & 1.95 & 1.14 & 1.60 & 1.99 & 0.70 & 1.42 & 1.96 \\
\hline
\end{tabular}




\section{Table 3 - (Continued)}

\begin{tabular}{|c|c|c|c|c|c|c|c|c|c|c|c|c|c|c|c|c|c|c|c|}
\hline \multirow[t]{3}{*}{ Process } & \multirow[t]{3}{*}{ Component } & \multicolumn{18}{|c|}{ Case } \\
\hline & & \multicolumn{2}{|c|}{ Single production } & \multicolumn{4}{|c|}{ Polygeneration-series production } & \multicolumn{6}{|c|}{ Polygeneration-parallel production } & \multicolumn{6}{|c|}{ Polygeneration-parallel-series production } \\
\hline & & 0 & 1 & 2 & $3(\mathrm{a})$ & $3(b)$ & $3(c)$ & $4(a)$ & $4(b)$ & $4(c)$ & $5(a)$ & $5(b)$ & $5(c)$ & $6(a)$ & $6(b)$ & $6(c)$ & $7(\mathrm{a})$ & $7(b)$ & $7(c)$ \\
\hline \multirow[t]{2}{*}{1} & $\begin{array}{l}\text { Electricity } \\
\text { requirement (MW) }\end{array}$ & 4.08 & 6.14 & 4.08 & 6.14 & 5.07 & 4.50 & 3.67 & 2.04 & 0.41 & 5.03 & 2.79 & 0.56 & 3.67 & 2.04 & 0.41 & 5.03 & 2.79 & 0.56 \\
\hline & $\begin{array}{l}\text { Normalised annual } \\
\text { operating cost (AOC) }\end{array}$ & 1.00 & 1.51 & 1.00 & 1.51 & 1.24 & 1.10 & 0.90 & 0.50 & 0.10 & 1.23 & 0.69 & 0.14 & 0.90 & 0.50 & 0.10 & 1.23 & 0.68 & 0.14 \\
\hline \multirow[t]{2}{*}{2} & $\begin{array}{l}\text { Electricity } \\
\text { requirement (MW) }\end{array}$ & 0.00 & 0.00 & 12.22 & 2.79 & 7.61 & 11.47 & 4.18 & 21.01 & 37.84 & 4.18 & 21.01 & 37.84 & 15.22 & 27.12 & 39.13 & 6.75 & 22.40 & 38.16 \\
\hline & $\begin{array}{l}\text { Normalised annual } \\
\text { operating cost (AOC) }\end{array}$ & 0.00 & 0.00 & 1.00 & 0.23 & 0.62 & 0.94 & 0.34 & 1.72 & 3.10 & 0.34 & 1.72 & 3.10 & 1.25 & 2.22 & 3.20 & 0.55 & 1.83 & 3.12 \\
\hline \multicolumn{20}{|l|}{ (d) } \\
\hline \multirow[t]{3}{*}{ Process } & Component & \multicolumn{18}{|c|}{ Case } \\
\hline & & \multicolumn{2}{|c|}{ Single production } & \multicolumn{4}{|c|}{ Polygeneration-Series Production } & \multicolumn{6}{|c|}{ Polygeneration-parallel production } & \multicolumn{6}{|c|}{ Polygeneration-parallel-series production } \\
\hline & & 0 & 1 & 2 & $3(a)$ & $3(b)$ & $3(c)$ & $4(a)$ & $4(b)$ & $4(c)$ & $5(a)$ & $5(b)$ & $5(c)$ & $6(a)$ & $6(b)$ & $6(c)$ & $7(\mathrm{a})$ & $7(b)$ & 7(c) \\
\hline \multirow[t]{6}{*}{1} & $\begin{array}{l}\text { Normalised annual } \\
\text { capital cost (ACC) }\end{array}$ & 1.00 & 1.42 & 1.00 & 1.42 & 1.13 & 1.03 & 0.94 & 0.66 & 0.25 & 1.32 & 0.93 & 0.35 & 0.94 & 0.66 & 0.25 & 1.32 & 0.93 & 0.35 \\
\hline & $\begin{array}{l}\text { Normalised annual } \\
\text { operating cost (AOC) }\end{array}$ & 1.00 & 1.51 & 1.00 & 1.51 & 1.24 & 1.10 & 0.90 & 0.50 & 0.10 & 1.23 & 0.69 & 0.14 & 0.90 & 0.50 & 0.10 & 1.23 & 0.68 & 0.14 \\
\hline & $\begin{array}{l}\text { Total annualised } \\
\text { cost (TAC) }\end{array}$ & 2.00 & 2.93 & 2.00 & 2.93 & 2.37 & 2.13 & 1.84 & 1.16 & 0.35 & 2.56 & 1.62 & 0.49 & 1.84 & 1.16 & 0.35 & 2.56 & 1.62 & 0.49 \\
\hline & Normalised TAC & 1.00 & 1.46 & 1.00 & 1.46 & 1.19 & 1.07 & 0.92 & 0.58 & 0.18 & 1.28 & 0.81 & 0.25 & 0.92 & 0.58 & 0.18 & 1.28 & 0.81 & 0.25 \\
\hline & $\Delta v_{p} / \Delta \mathrm{TAC}$ & 1.00 & 0.92 & 1.00 & 0.92 & 1.00 & 0.97 & 0.98 & 0.86 & 0.57 & 0.94 & 0.83 & 0.55 & 0.98 & 0.86 & 0.57 & 0.94 & 0.83 & 0.55 \\
\hline & $\Delta v_{f} / \Delta \mathrm{TAC}$ & 1.00 & 0.68 & 1.00 & 0.68 & 0.84 & 0.94 & 0.98 & 0.86 & 0.57 & 0.70 & 0.62 & 0.41 & 0.98 & 0.86 & 0.57 & 0.70 & 0.62 & 0.41 \\
\hline \multirow[t]{6}{*}{2} & $\begin{array}{l}\text { Normalised annual } \\
\text { capital cost (ACC) }\end{array}$ & 0.00 & 0.00 & 1.00 & 0.42 & 0.76 & 0.96 & 0.52 & 1.37 & 1.95 & 0.52 & 1.37 & 1.95 & 1.14 & 1.60 & 1.99 & 0.70 & 1.42 & 1.96 \\
\hline & $\begin{array}{l}\text { Normalised annual } \\
\text { operating cost (AOC) }\end{array}$ & 0.00 & 0.00 & 1.00 & 0.23 & 0.62 & 0.94 & 0.34 & 1.72 & 3.10 & 0.34 & 1.72 & 3.10 & 1.25 & 2.22 & 3.20 & 0.55 & 1.83 & 3.12 \\
\hline & $\begin{array}{l}\text { Total annualised } \\
\text { cost (TAC) }\end{array}$ & 0.00 & 0.00 & 2.00 & 0.65 & 1.38 & 1.90 & 0.86 & 3.09 & 5.04 & 0.86 & 3.09 & 5.04 & 2.38 & 3.82 & 5.19 & 1.25 & 3.26 & 5.08 \\
\hline & Normalised TAC & 0.00 & 0.00 & 1.00 & 0.33 & 0.69 & 0.95 & 0.43 & 1.54 & 2.52 & 0.43 & 1.54 & 2.52 & 1.19 & 1.91 & 2.59 & 0.63 & 1.63 & 2.54 \\
\hline & $\Delta v_{p} / \Delta \mathrm{TAC}$ & 0.00 & 0.00 & 1.00 & 0.76 & 0.92 & 0.99 & 0.77 & 1.08 & 1.19 & 0.77 & 1.08 & 1.19 & 1.04 & 1.13 & 1.20 & 0.89 & 1.10 & 1.19 \\
\hline & $\Delta v_{f} / \Delta \mathrm{TAC}$ & 0.00 & 0.00 & 1.00 & 0.29 & 0.67 & 0.94 & 0.45 & 1.61 & 2.63 & 0.45 & 1.61 & 2.63 & 1.20 & 1.97 & 2.70 & 0.61 & 1.68 & 2.64 \\
\hline
\end{tabular}


the stream results obtained from simulation. $\mathrm{LHV}_{\text {feed }}$ together with the corresponding conversion factor $\lambda$ can be found in Table 4.

$\mathrm{LHV}_{\text {electricity }}=\mathrm{LHV}_{\text {feed }} \times \lambda$

For methanol synthesis process (Process 1),

Process GHG Intensity with economic implication

$=\mathrm{GHGI} \times \operatorname{LHV}_{p} \times \frac{\Delta v_{p}}{\Delta \mathrm{TAC}}$

$=\frac{\mathrm{GHG}_{i}^{\text {gen,net }}}{E \mathrm{p}_{i}} \times \mathrm{LHV}_{p} \times \frac{\Delta v_{p}}{\Delta \mathrm{TAC}}$

$=\left[\frac{(2.66-1.02) \mathrm{t} / \mathrm{h}}{245.1 \mathrm{MW}} \times \frac{1000 \mathrm{~kg} / \mathrm{t}}{3600 \mathrm{MJ} / \mathrm{MWh}}\right] \times 20.1 \mathrm{MJ} / \mathrm{kg} \times 1$

$=0.037$

Similarly, for electricity generation process (Process 2), Process GHG Intensity with economic implication

$=G H G I \times \operatorname{LHV}_{p} \times \frac{\Delta v_{p}}{\Delta \mathrm{TAC}}$

$=\frac{\mathrm{GHG}_{i}^{\text {gen,net }}}{\mathrm{Ep}_{\mathrm{i}}} \times \mathrm{LHV}_{p} \times \frac{\Delta \mathrm{v}_{p}}{\Delta \mathrm{TAC}}$

$=\left[\frac{(22.73-2.23) \mathrm{t} / \mathrm{h}}{25.4 \mathrm{MW}} \times \frac{1000 \mathrm{~kg} / \mathrm{t}}{3600 \mathrm{MJ} / \mathrm{MWh}}\right] \times 3.805 \mathrm{MJ} / \mathrm{kg} \times 1$

$=0.853$

where

$\mathrm{LHV}_{p}=\mathrm{LHV}_{\text {electricity }}$

$=\operatorname{LHV}_{\text {feed }} \times \lambda$

$=18.1 \mathrm{MJ} / \mathrm{kg} \times \frac{25.4 \mathrm{MW}}{120.82 \mathrm{MW}}$

$=3.805 \mathrm{MJ} / \mathrm{kg}$

For process recoverable energy assessment, heat released from methanol synthesis reactor (Process 1) and HRSG (Process 2) are considered as important heat sources and can potentially be recovered.

The economic worthiness with respect to feed, $\Delta v_{f} / \Delta$ TAC is evaluated using Eq. (10b). Note that in this case, $k=0$ since Case 2 is the base case.

For methanol synthesis process (Process 1),

$$
\begin{aligned}
{\left[\frac{\Delta v_{f}}{\Delta \mathrm{TAC}}\right]_{k, 0} } & =\frac{q_{f, k} / q_{f, 0}}{\text { Normalised } \mathrm{TAC}_{k, 0}}=\frac{420.17 \mathrm{MW} / 420.17 \mathrm{MW}}{1} \\
& =1
\end{aligned}
$$

Similarly, for electricity generation process (Process 2),

$$
\begin{aligned}
{\left[\frac{\Delta v_{f}}{\Delta \mathrm{TAC}}\right]_{k, 0} } & =\frac{q_{f, k} / q_{f, 0}}{\text { Normalised } \mathrm{TAC}_{k, 0}}=\frac{120.82 \mathrm{MW} / 120.82 \mathrm{MW}}{1} \\
& =1
\end{aligned}
$$

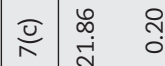

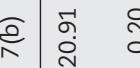

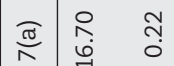

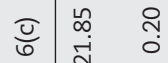

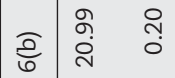

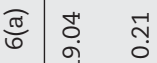

ㄴํํ ำ ำ

ํํํ \&

๙ึำ

ปิ

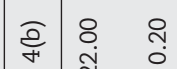

๙

गु

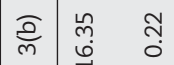

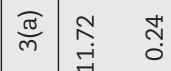

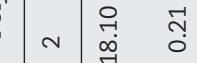

$+1 \quad 80$

- 80

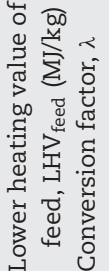


For methanol synthesis process (Process 1),

Process Energy Recovery with economic implication

$$
\begin{aligned}
& =\mathrm{ER} \times \frac{\Delta v_{f}}{\Delta \mathrm{TAC}} \\
& =\frac{\mathrm{H}_{\mathrm{i}}}{\mathrm{Ef}_{\mathrm{i}}} \times \frac{\Delta v_{f}}{\Delta \mathrm{TAC}} \\
& =\frac{37.12 \mathrm{MW}}{420.17 \mathrm{MW}} \times 1 \\
& =0.088
\end{aligned}
$$

Similarly, for electricity generation process (Process 2), Process Energy Recovery with economic implication

$$
\begin{aligned}
& =\mathrm{ER} \times \frac{\Delta v_{f}}{\Delta \mathrm{TAC}} \\
& =\frac{\mathrm{H}_{\mathrm{i}}}{\mathrm{Ef}_{\mathrm{i}}} \times \frac{\Delta v_{f}}{\Delta \mathrm{TAC}} \\
& =\frac{32.0 \mathrm{MW}}{120.82 \mathrm{MW}} \times 1 \\
& =0.265
\end{aligned}
$$

Eq. (11g) has been applied to calculate the 3E performance of the polygeneration system Case 2 by incorporating process energy intensity, process GHG intensity and process recoverable energy components for Processes 1 and 2, as evaluated above.

$$
\begin{aligned}
I_{3 E} & =\sum_{i=1}^{n}\left[\mathrm{EI}_{i} \times\left(\frac{\Delta v_{p}}{\Delta \mathrm{TAC}}\right)_{i}\right]+\sum_{i=1}^{n}\left[\mathrm{GHGI}_{i} \times \mathrm{LHV}_{p, i} \times\left(\frac{\Delta v_{p}}{\Delta \mathrm{TAC}}\right)_{i}\right] \\
& -\sum_{i=1}^{n}\left[E R_{i} \times\left(\frac{\Delta v_{f}}{\Delta \mathrm{TAC}}\right)_{i}\right] \\
& =(0.017+0.482)+(0.037+0.853)-(0.088+0.265) \\
& =1.036
\end{aligned}
$$

Table 5(a)-(c) present the summary of 3E assessment for single and series, parallel and parallel-series configurations, respectively. The $3 \mathrm{E}$ index, $\mathrm{I}_{3 \mathrm{E}}$ has also been determined for each case using Eq. (11f) for single production system and Eq. (11g) for polygeneration system. Note that GHGI in Eqs. (11d), (11f) and (11g) have been replaced by $\mathrm{CO}_{2} \mathrm{I}$ in Table 5 since only $\mathrm{CO}_{2}$ is particularly involved in the system.

\section{Discussion}

\subsection{Insights from $O B$ analysis}

From the $\mathrm{OB}$ analysis performed on the systems shown in Figs. 5-8, results presented in Table 2 and Fig. 9, the following observations are obtained:

- Series production system (Fig. 6): This system generally outscores the performance of the base case with once-through single production system (Case 0). Recycle configuration (Case 3) has a higher energy and economic performances as well as lower $\mathrm{CO}_{2}$ emission compared to the once-through system (Case 2). Recycle configuration also tends to show salient benefit for higher recycle flow into methanol production, i.e. $90 \%$. This is demonstrated in the Production Feasibility Plot in Fig. 9(a).

- Parallel production system (Fig. 7): This system generally shows lower energy and economic performance and higher
$\mathrm{CO}_{2}$ emission compared to the base case with once-through single production system (Case 0 ). This can be seen in the Production Feasibility Plot in Fig. 9(b) that the corresponding cases fall below $E c=1$. There is an exception of which the parallel system can perform better than the base case, if major proportion of syngas (i.e. $90 \%$ ) and high recycle flow (i.e. $90 \%$ ) are used for methanol production, as demonstrated in Case 5(a).

- Parallel-series production system (Fig. 8): The Production Feasibility Plot in Fig. 9(c) indicates that the system has a lower performance compared to the base case, unless $90 \%$ syngas feed is used into methanol production system either through once-through (Case 6(a)) or 90\% recycle configuration (Case 7(a)).

- Putting together the chosen best performed cases from each category of production system for overall comparison (Fig. 9(d)), it can be seen that Cases 2 and 3(a) are the "winner", followed by Cases 5(a) and 7(a).

$\mathrm{OB}$ analysis concludes that series and recycle configuration and higher utilisation of syngas feed into methanol synthesis are the keys in generating a highly efficient system. Parallel configuration is generally not favourable within the current context (the outcome could be different if different process and combination of products other than methanol and electricity are selected). In terms of $\mathrm{CO}_{2}$ emission, there is a trend shown in Table 2 that higher utilisation of syngas into methanol synthesis instead of electricity generation has a potential of lowering the $\mathrm{CO}_{2}$ emission. This is mainly because electricity generation involves combustion and releases significant amount of $\mathrm{CO}_{2}$. Although $\mathrm{OB}$ analysis provides directional information on which cases are preferable, there is no information showing the worthiness of the modification or improvement on the systems. A further assessment using IB analysis should be conducted to investigate the source and generation of $\mathrm{CO}_{2}$.

\subsection{Insights from IB analysis}

Economic analysis using scale factor method presented in Table 3 reflects the economic worthiness of the design options under consideration, embracing individual processes within the system. The variations in relative ACC, relative AOC and TAC with reference to Case 2 (new base case in IB analysis) are summarised in Table 3(b)-(d), respectively. It can be observed that TAC varies significantly with the degree of production in Process 2, i.e. electricity generation. ACC is predominantly contributed by Process 2, i.e. when more syngas is fed into electricity generation. Similar trend can be observed for AOC due to electricity demand is heavily weighted towards the air compression in Process 2. Although recycle configuration involves higher syngas compression power, the extent of which is much less than the power required by the air compressor. In general, series configuration is preferred over parallel or parallel-series configuration in terms of having relatively lower ACC and AOC. Nevertheless, the economic worthiness (Eqs. (10a) and $(10 b)$ ) is a vital indicator in assessing polygeneration systems because the synergies between the value of feed or product and TAC determine whether a particular design is economically worthwhile. An interesting point shown in Table $3(\mathrm{~d})$ is that the relative $\Delta v_{p} / \Delta T A C$ in Process 1 for all cases are either similar or lower compared to the base case (Case 2), while improvement in $\Delta v_{p} / \Delta$ TAC compared to the base case can be observed in Process 2 for cases with more syngas is utilised 
Table 5 - Inside boundary (IB) analysis using 3E assessment consisting of process energy intensity, process GHG intensity and process energy recovery assessment. (a) single and polygeneration- series production cases; (b) polygeneration- parallel production cases; (c) polygeneration- parallel-series production cases. (a).

\begin{tabular}{|c|c|c|c|c|c|c|c|c|c|c|c|c|}
\hline \multirow[t]{4}{*}{ Component } & \multicolumn{12}{|c|}{ Case } \\
\hline & \multicolumn{4}{|c|}{ Single production } & \multicolumn{8}{|c|}{ Polygeneration-series production } \\
\hline & \multicolumn{2}{|c|}{0} & \multicolumn{2}{|c|}{1} & \multicolumn{2}{|c|}{2} & \multicolumn{2}{|c|}{ 3(a) } & \multicolumn{2}{|c|}{$3(b)$} & \multicolumn{2}{|c|}{ 3(c) } \\
\hline & Process 1 & Process 2 & Process 1 & Process 2 & Process 1 & Process 2 & Process 1 & Process 2 & Process 1 & Process 2 & Process 1 & Process 2 \\
\hline \multicolumn{13}{|l|}{ Process energy intensity assessment } \\
\hline Net power demand, $E D^{\text {net }}(\mathrm{MW})$ & 4.08 & 0.00 & 6.14 & 0.00 & 4.08 & 12.22 & 6.14 & 2.79 & 5.07 & 7.61 & 4.50 & 11.47 \\
\hline Energy value of product, Ep (MW) & 245.11 & 0.00 & 328.30 & 0.00 & 245.11 & 25.35 & 328.30 & 6.30 & 291.73 & 16.10 & 252.29 & 23.81 \\
\hline $\begin{array}{l}\text { Process energy intensity, EI (MW/MW } \\
\text { product) }\end{array}$ & 0.017 & 0.000 & 0.019 & 0.000 & 0.017 & 0.482 & 0.019 & 0.443 & 0.017 & 0.473 & 0.018 & 0.482 \\
\hline$\Delta v_{p} / \Delta \mathrm{TAC}$ & 1.000 & 0.000 & 0.915 & 0.000 & 1.000 & 1.000 & 0.915 & 0.764 & 1.004 & 0.920 & 0.966 & 0.988 \\
\hline \multirow[t]{2}{*}{$\mathrm{EI} \times \Delta v_{p} / \Delta \mathrm{TAC}$} & 0.017 & 0.000 & 0.017 & 0.000 & 0.017 & 0.482 & 0.017 & 0.338 & 0.017 & 0.435 & 0.017 & 0.476 \\
\hline & \multicolumn{2}{|c|}{0.017} & \multicolumn{2}{|c|}{0.017} & \multicolumn{2}{|c|}{0.499} & \multicolumn{2}{|c|}{0.355} & \multicolumn{2}{|c|}{0.453} & \multicolumn{2}{|c|}{0.493} \\
\hline \multicolumn{13}{|l|}{ Process GHG intensity assessment } \\
\hline $\mathrm{CO}_{2}$ emission, $\mathrm{CO}_{2}{ }^{\mathrm{emi}}(\mathrm{t} / \mathrm{h})$ & 2.66 & 0.00 & 1.83 & 0.00 & 2.66 & 22.73 & 1.83 & 2.94 & 2.58 & 12.99 & 2.65 & 21.10 \\
\hline $\mathrm{CO}_{2}$ in feed, $\mathrm{CO}_{2}$ feed $(\mathrm{t} / \mathrm{h})$ & 1.02 & 0.00 & 1.02 & 0.00 & 1.02 & 2.23 & 1.02 & 0.96 & 1.02 & 1.92 & 1.02 & 2.19 \\
\hline Net $\mathrm{CO}_{2}$ generation, $\mathrm{CO}_{2}$ gen,net $(\mathrm{t} / \mathrm{h})$ & 1.64 & 0.00 & 0.81 & 0.00 & 1.64 & 20.50 & 0.81 & 1.98 & 1.55 & 11.06 & 1.63 & 18.91 \\
\hline $\begin{array}{l}\text { Process } \mathrm{CO}_{2} \text { intensity, } \mathrm{CO}_{2} \mathrm{I}(\mathrm{kg} / \mathrm{MJ} \\
\text { product) }\end{array}$ & 0.0019 & 0.000 & 0.0007 & 0.000 & 0.0019 & 0.225 & 0.0007 & 0.087 & 0.0015 & 0.191 & 0.0018 & 0.221 \\
\hline $\mathrm{CO}_{2} \mathrm{I} \times \mathrm{LHV}_{p}$ & 0.037 & 0.000 & 0.014 & 0.000 & 0.037 & 0.853 & 0.014 & 0.244 & 0.030 & 0.672 & 0.036 & 0.833 \\
\hline$\Delta v_{p} / \Delta \mathrm{TAC}$ & 1.000 & 0.000 & 0.915 & 0.000 & 1.000 & 1.000 & 0.915 & 0.764 & 1.004 & 0.920 & 0.966 & 0.988 \\
\hline \multirow[t]{2}{*}{$\mathrm{CO}_{2} \mathrm{I} \times \mathrm{LHV}_{p} \times \Delta v_{p} / \Delta \mathrm{TAC}$} & 0.037 & 0.000 & 0.013 & 0.000 & 0.037 & 0.853 & 0.013 & 0.186 & 0.030 & 0.619 & 0.035 & 0.823 \\
\hline & \multicolumn{2}{|c|}{0.037} & \multicolumn{2}{|c|}{0.013} & \multicolumn{2}{|c|}{0.890} & \multicolumn{2}{|c|}{0.199} & \multicolumn{2}{|c|}{0.649} & \multicolumn{2}{|c|}{0.858} \\
\hline \multicolumn{13}{|l|}{ Process recoverable energy assessment } \\
\hline Total heat released, $\mathrm{H}(\mathrm{MW})$ & -37.12 & 0.00 & -48.09 & 0.00 & -37.12 & -32.00 & -48.10 & -7.55 & -42.93 & -20.12 & -38.41 & -30.02 \\
\hline Energy value of feed, Ef (MW) & 420.17 & 0.00 & 420.17 & 0.00 & 420.17 & 120.82 & 420.17 & 26.40 & 420.17 & 74.73 & 420.17 & 112.65 \\
\hline \multicolumn{12}{|l|}{ (MW/MW feed) } & 0.266 \\
\hline$\Delta v_{f} / \Delta \mathrm{TAC}$ & 1.000 & 0.000 & 0.683 & 0.000 & 1.000 & 1.000 & 0.683 & 0.286 & 0.844 & 0.672 & 0.938 & 0.944 \\
\hline$E R \times \Delta v_{f} / \Delta T A C$ & 0.088 & 0.000 & 0.078 & 0.000 & 0.088 & 0.265 & 0.078 & 0.082 & 0.086 & 0.181 & 0.086 & 0.251 \\
\hline & & & & & & & & & & & & \\
\hline Relative 3E Index, I $3 \mathrm{E}$ (Inc. ER) & & & & & & & & & & & & \\
\hline Relative 3E Index, I $I_{3 E}$ (Exc. ER) & & & & & & & & 54 & & & & \\
\hline
\end{tabular}




\section{Table 5 - (Continued)}

(b)

\begin{tabular}{|c|c|c|c|c|c|c|c|c|c|c|c|c|}
\hline \multirow[t]{4}{*}{ Component } & \multicolumn{12}{|c|}{ Case } \\
\hline & \multicolumn{12}{|c|}{ Polygeneration-parallel production } \\
\hline & \multicolumn{2}{|c|}{$4(\mathrm{a})$} & \multicolumn{2}{|c|}{$4(\mathrm{~b})$} & \multicolumn{2}{|c|}{$4(c)$} & \multicolumn{2}{|c|}{$5(a)$} & \multicolumn{2}{|c|}{$5(b)$} & \multicolumn{2}{|c|}{ 5(c) } \\
\hline & Process 1 & Process 2 & Process 1 & Process 2 & Process 1 & Process 2 & Process 1 & Process 2 & Process 1 & Process 2 & Process 1 & Process 2 \\
\hline \multicolumn{13}{|l|}{ Process energy intensity assessment } \\
\hline Net power demand, $E D^{\text {net }}(\mathrm{MW})$ & 3.67 & 4.18 & 2.04 & 21.01 & 0.41 & 37.84 & 5.03 & 4.18 & 2.79 & 21.01 & 0.56 & 37.84 \\
\hline Energy value of product, Ep (MW) & 220.61 & 8.41 & 122.56 & 42.19 & 24.51 & 75.97 & 295.65 & 8.41 & 164.25 & 42.19 & 32.85 & 75.97 \\
\hline Process energy intensity, EI (MW/MW product) & 0.017 & 0.497 & 0.017 & 0.498 & 0.017 & 0.498 & 0.017 & 0.497 & 0.017 & 0.498 & 0.017 & 0.498 \\
\hline$\Delta v_{p} / \Delta \mathrm{TAC}$ & 0.979 & 0.770 & 0.862 & 1.078 & 0.570 & 1.189 & 0.943 & 0.770 & 0.830 & 1.078 & 0.546 & 1.189 \\
\hline \multirow[t]{2}{*}{$\mathrm{EI} \times \Delta v_{p} / \Delta \mathrm{TAC}$} & 0.016 & 0.383 & 0.014 & 0.537 & 0.009 & 0.592 & 0.016 & 0.383 & 0.014 & 0.537 & 0.009 & 0.592 \\
\hline & \multicolumn{2}{|c|}{0.399} & \multicolumn{2}{|c|}{0.551} & \multicolumn{2}{|c|}{0.602} & \multicolumn{2}{|c|}{0.399} & \multicolumn{2}{|c|}{0.551} & \multicolumn{2}{|c|}{0.601} \\
\hline \multicolumn{13}{|l|}{ Process GHG Intensity Assessment } \\
\hline $\mathrm{CO}_{2}$ emission, $\mathrm{CO}_{2}{ }^{\mathrm{emi}}(\mathrm{t} / \mathrm{h})$ & 2.39 & 8.43 & 1.33 & 42.50 & 0.27 & 76.58 & 1.65 & 8.43 & 0.92 & 42.50 & 0.18 & 76.58 \\
\hline $\mathrm{CO}_{2}$ in feed, $\mathrm{CO}_{2}$ feed $(\mathrm{t} / \mathrm{h})$ & 0.92 & 0.10 & 0.51 & 0.51 & 0.10 & 0.92 & 0.92 & 0.10 & 0.51 & 0.51 & 0.10 & 0.92 \\
\hline Net $\mathrm{CO}_{2}$ generation, $\mathrm{CO}_{2}$ gen,net $(\mathrm{t} / \mathrm{h})$ & 1.47 & 8.33 & 0.82 & 41.99 & 0.16 & 75.66 & 0.73 & 8.33 & 0.41 & 41.99 & 0.08 & 75.66 \\
\hline Process $\mathrm{CO}_{2}$ intensity, $\mathrm{CO}_{2} \mathrm{I}$ (kg/MJ product) & 0.0019 & 0.275 & 0.0019 & 0.276 & 0.0019 & 0.277 & 0.0007 & 0.275 & 0.0007 & 0.276 & 0.0007 & 0.277 \\
\hline $\mathrm{CO}_{2} \mathrm{I} \times \mathrm{LHV}_{p}$ & 0.037 & 1.212 & 0.037 & 1.222 & 0.037 & 1.224 & 0.014 & 1.212 & 0.014 & 1.222 & 0.014 & 1.224 \\
\hline$\Delta v_{p} / \Delta \mathrm{TAC}$ & 0.979 & 0.770 & 0.862 & 1.078 & 0.570 & 1.189 & 0.943 & 0.770 & 0.830 & 1.078 & 0.546 & 1.189 \\
\hline \multirow{2}{*}{$\mathrm{CO}_{2} \mathrm{I} \times \mathrm{LHV}_{p} \times \Delta v_{p} / \Delta \mathrm{TAC}$} & 0.036 & 0.934 & 0.032 & 1.318 & 0.021 & 1.454 & 0.013 & 0.934 & 0.011 & 1.318 & 0.008 & 1.454 \\
\hline & \multicolumn{2}{|c|}{0.970} & \multicolumn{2}{|c|}{1.350} & \multicolumn{2}{|c|}{1.476} & \multicolumn{2}{|c|}{0.947} & \multicolumn{2}{|c|}{1.330} & \multicolumn{2}{|c|}{1.462} \\
\hline \multicolumn{13}{|l|}{ Process recoverable energy assessment } \\
\hline Total heat released, $\mathrm{H}(\mathrm{MW})$ & -33.41 & -10.63 & -18.56 & -53.38 & -3.71 & -96.12 & -42.79 & -10.63 & -23.77 & -53.38 & -4.75 & -96.12 \\
\hline Energy value of feed, $E f(M W)$ & 377.80 & 41.98 & 209.89 & 209.89 & 41.98 & 377.80 & 377.80 & 41.98 & 209.89 & 209.89 & 41.98 & 377.80 \\
\hline Process recoverable energy, ER (MW/MW feed) & 0.088 & 0.253 & 0.088 & 0.254 & 0.088 & 0.254 & 0.113 & 0.253 & 0.113 & 0.254 & 0.113 & 0.254 \\
\hline$\Delta v_{f} / \Delta \mathrm{TAC}$ & 0.978 & 0.451 & 0.862 & 1.611 & 0.569 & 2.631 & 0.703 & 0.451 & 0.618 & 1.611 & 0.407 & 2.631 \\
\hline \multirow[t]{2}{*}{$\mathrm{ER} \times \Delta v_{f} / \Delta \mathrm{TAC}$} & 0.086 & 0.114 & 0.076 & 0.410 & 0.050 & 0.669 & 0.080 & 0.114 & 0.070 & 0.410 & 0.046 & 0.669 \\
\hline & \multicolumn{2}{|c|}{0.201} & & & & & & 94 & & & & \\
\hline Relative 3E Index, $I_{3 E}$ (Inc. ER) & & & & & & & & 52 & & & & \\
\hline Relative 3E Index, I $I_{3 E}$ (Exc. ER) & & & & & & & & 45 & & 81 & & \\
\hline
\end{tabular}


Table 5 - (Continued)

(c)

\begin{tabular}{|c|c|c|c|c|c|c|c|c|c|c|c|c|}
\hline \multirow[t]{4}{*}{ Component } & \multicolumn{12}{|c|}{ Case } \\
\hline & \multicolumn{12}{|c|}{ Polygeneration- Parallel-Series Production } \\
\hline & \multicolumn{2}{|c|}{$6(\mathrm{a})$} & \multicolumn{2}{|c|}{ 6(b) } & \multicolumn{2}{|c|}{ 6(c) } & \multicolumn{2}{|c|}{$7(\mathrm{a})$} & \multicolumn{2}{|c|}{$7(\mathrm{~b})$} & \multicolumn{2}{|c|}{$7(\mathrm{c})$} \\
\hline & Process 1 & Process 2 & Process 1 & Process 2 & Process 1 & Process 2 & Process 1 & Process 2 & Process 1 & Process 2 & Process 1 & Process 2 \\
\hline \multicolumn{13}{|l|}{ Process energy intensity assessment } \\
\hline Net power demand, ED ${ }^{\text {net }}(\mathrm{MW})$ & 3.67 & 15.22 & 2.04 & 27.12 & 0.41 & 39.13 & 5.03 & 6.75 & 2.79 & 22.40 & 0.56 & 38.16 \\
\hline Energy value of product, Ep (MW) & 220.61 & 31.28 & 122.56 & 54.87 & 24.51 & 78.61 & 295.65 & 14.18 & 164.25 & 45.34 & 32.85 & 76.67 \\
\hline Process energy intensity, EI (MW/MW product) & 0.017 & 0.487 & 0.017 & 0.494 & 0.017 & 0.498 & 0.017 & 0.476 & 0.017 & 0.494 & 0.017 & 0.498 \\
\hline$\Delta v_{p} / \Delta \mathrm{TAC}$ & 0.979 & 1.036 & 0.862 & 1.134 & 0.570 & 1.195 & 0.944 & 0.892 & 0.830 & 1.098 & 0.546 & 1.191 \\
\hline \multirow[t]{2}{*}{$\mathrm{EI} \times \Delta v_{p} / \Delta \mathrm{TAC}$} & 0.016 & 0.504 & 0.014 & 0.560 & 0.009 & 0.595 & 0.016 & 0.425 & 0.014 & 0.543 & 0.009 & 0.593 \\
\hline & \multicolumn{2}{|c|}{0.520} & \multicolumn{2}{|c|}{0.575} & \multicolumn{2}{|c|}{0.605} & \multicolumn{2}{|c|}{0.441} & \multicolumn{2}{|c|}{0.557} & \multicolumn{2}{|c|}{0.602} \\
\hline \multicolumn{13}{|l|}{ Process GHG intensity assessment } \\
\hline $\mathrm{CO}_{2}$ emission, $\mathrm{CO}_{2}{ }^{\mathrm{emi}}(\mathrm{t} / \mathrm{h})$ & 2.39 & 29.03 & 1.33 & 53.87 & 0.27 & 78.90 & 1.65 & 11.16 & 0.92 & 43.97 & 0.18 & 76.91 \\
\hline $\mathrm{CO}_{2}$ in feed, $\mathrm{CO}_{2}$ feed $(\mathrm{t} / \mathrm{h})$ & 0.92 & 2.11 & 0.51 & 1.63 & 0.10 & 1.14 & 0.92 & 0.96 & 0.51 & 0.99 & 0.10 & 1.02 \\
\hline Net $\mathrm{CO}_{2}$ generation, $\mathrm{CO}_{2}$ gen,net $(\mathrm{t} / \mathrm{h})$ & 1.47 & 26.92 & 0.82 & 52.24 & 0.16 & 77.76 & 0.73 & 10.19 & 0.41 & 42.98 & 0.08 & 75.90 \\
\hline Process $\mathrm{CO}_{2}$ intensity, $\mathrm{CO}_{2} \mathrm{I}(\mathrm{kg} / \mathrm{MJ}$ product) & 0.0019 & 0.239 & 0.0019 & 0.264 & 0.0019 & 0.275 & 0.0007 & 0.200 & 0.0007 & 0.263 & 0.0007 & 0.275 \\
\hline $\mathrm{CO}_{2} \mathrm{I} \times \mathrm{LHV}_{p}$ & 0.037 & 0.945 & 0.037 & 1.127 & 0.037 & 1.210 & 0.014 & 0.719 & 0.014 & 1.119 & 0.014 & 1.212 \\
\hline$\Delta v_{p} / \Delta \mathrm{TAC}$ & 0.979 & 1.036 & 0.862 & 1.134 & 0.570 & 1.195 & 0.944 & 0.892 & 0.830 & 1.098 & 0.546 & 1.191 \\
\hline \multirow{2}{*}{$\mathrm{CO}_{2} \mathrm{I} \times \mathrm{LHV}_{p} \times \Delta v_{p} / \Delta \mathrm{TAC}$} & 0.036 & 0.978 & 0.032 & 1.278 & 0.021 & 1.447 & 0.013 & 0.642 & 0.011 & 1.229 & 0.008 & 1.443 \\
\hline & \multicolumn{2}{|c|}{1.015} & \multicolumn{2}{|c|}{1.310} & \multicolumn{2}{|c|}{1.468} & \multicolumn{2}{|c|}{0.655} & \multicolumn{2}{|c|}{1.240} & \multicolumn{2}{|c|}{1.450} \\
\hline \multicolumn{13}{|l|}{ Process recoverable energy assessment } \\
\hline Total heat released, $H$ (MW) & -33.41 & -39.52 & -18.56 & -69.38 & -3.71 & -99.43 & -42.78 & -17.55 & -23.77 & -57.15 & -4.75 & -96.95 \\
\hline Energy value of feed, Ef (MW) & 377.80 & 150.72 & 209.89 & 270.30 & 41.98 & 389.88 & 377.80 & 65.74 & 209.89 & 223.09 & 41.98 & 380.44 \\
\hline Process recoverable energy, ER (MW/MW feed) & 0.088 & 0.262 & 0.088 & 0.257 & 0.088 & 0.255 & 0.113 & 0.267 & 0.113 & 0.256 & 0.113 & 0.255 \\
\hline$\Delta v_{f} / \Delta \mathrm{TAC}$ & 0.978 & 1.204 & 0.862 & 1.973 & 0.569 & 2.699 & 0.703 & 0.610 & 0.619 & 1.682 & 0.407 & 2.644 \\
\hline \multirow[t]{2}{*}{$\mathrm{ER} \times \Delta v_{f} / \Delta \mathrm{TAC}$} & 0.086 & 0.316 & 0.076 & 0.506 & 0.050 & 0.688 & 0.080 & 0.163 & 0.070 & 0.431 & 0.046 & 0.674 \\
\hline & \multicolumn{2}{|c|}{0.402} & & & & 39 & & 42 & & & & \\
\hline Relative 3E Index, I $3 \mathrm{E}$ (Inc. ER) & & & & & & & & 53 & & & & \\
\hline Relative 3E Index, I $3 \mathrm{E}$ (Exc. ER) & & & & & & & & 96 & & & & \\
\hline
\end{tabular}


into electricity generation and that previously has been identified to be a costly process. This again suggests that an economic indicator cannot be used solely to justify the feasibility and favourability of a design. The variation of economic worthiness on the overall impact and the corresponding significance in the context of sustainability would become more evident when it is coupled with other sustainability criteria. On the other hand, the economic worthiness with respect to value of feed $\left(\Delta v_{f} / \Delta T A C\right)$ is not relevant in the current scenario where only single and same type of feed (syngas) is used. However, it should be applied in Eqs. (11f) and (11g) in order to conform to the convention.

Process energy intensity, process GHG intensity and process recoverable energy, synergised with economic worthiness have been evaluated and presented in Table 5. The single production systems (Cases 1 and 2) should be separated from the polygeneration systems (Cases 3-7) for the sake of comparison on a like-to-like basis. The following observation can be obtained for each system performance criteria:

- Process energy intensity (EI): EI is the same for Processes 1 and 2 , respectively in all cases. This is because the modification of the system is made through altering the configuration, and not on the operating conditions of the respective process units. Therefore, the economic worthiness of EI, termed as $\mathrm{EI} \times\left(\Delta v_{p} / \Delta \mathrm{TAC}\right)$, is mainly influenced by $\Delta v_{p} / \Delta \mathrm{TAC}$. Lower $\mathrm{EI} \times\left(\Delta v_{p} / \Delta \mathrm{TAC}\right)$ is desirable since it implies that the economic value-to-investment placed on energy intensity is less significant. It can be seen that $\mathrm{EI} \times\left(\Delta v_{p} / \Delta \mathrm{TAC}\right)$ is lower when high recycle flowrate and/or higher proportion of syngas is utilised for Process 1, such as in Cases 3(a), 4(a), 5(a), 6(a) and 7(a).

- Process GHG $\left(\mathrm{CO}_{2}\right)$ intensity $\left(\mathrm{CO}_{2} \mathrm{I}\right)$ : The economic worthiness of $\mathrm{CO}_{2} \mathrm{I}$, termed as $\mathrm{CO}_{2} \mathrm{I} \times \mathrm{LHV}_{p} \times\left(\Delta \mathrm{v}_{p} / \Delta \mathrm{TAC}\right)$, carries significant impact on the overall system performance and it has a great variation across each design option. Lower $\mathrm{CO}_{2} \mathrm{I} \times \mathrm{LHV}_{p} \times\left(\Delta \mathrm{v}_{p} / \Delta \mathrm{TAC}\right)$ is desirable since it implies that the economic value-to-investment placed on GHG intensity is less significant. Parallel and parallel-series systems are generally not favourable in terms of resulting in high $\mathrm{CO}_{2} \mathrm{I} \times \mathrm{LHV}_{p} \times\left(\Delta \mathrm{v}_{p} / \Delta \mathrm{TAC}\right)$. This is primarily attributed to Process 2 where mostly $\mathrm{CO}_{2}$ is generated from the syngas combustion process. $\mathrm{CO}_{2} \mathrm{I}$ is different in series and parallelseries configurations, while similar $\mathrm{CO}_{2} \mathrm{I}$ can be observed in parallel cases. The variation in $\mathrm{CO}_{2} \mathrm{I}$ is mainly affected by the $\mathrm{CO}$ and $\mathrm{H}_{2}$ composition in the syngas feed which is to be used in the combustion process. Parallel configuration has the same $\mathrm{CO}$ and $\mathrm{H}_{2}$ composition due to the split syngas feed stream, which is fractionally similar to Process 1 and Process 2. Series system has relatively lower $\mathrm{CO}_{2} \mathrm{I}$ because most of $\mathrm{CO}$ and $\mathrm{H}_{2}$ in the syngas have been used in Process 1 for methanol synthesis prior to electricity generation in Process 2.

- Process recoverable energy (ER): ER is generally dominated by Process 2, i.e. energy recovery through HRSG unit. Nevertheless, the economic worthiness of recoverable energy of Process 2 is relatively lower than Process 1 in certain cases, i.e. Cases 4(c), 5(c), 6(c) and 7(c) where the systems involve parallel and parallel-series configurations and that the capacity of power generation is significantly lower compared to methanol production. The economic worthiness of $\mathrm{ER}$, termed as $\mathrm{ER} \times\left(\Delta v_{f} / \Delta \mathrm{TAC}\right)$, has a remediation effect on the overall performance. Higher $\operatorname{ER} \times\left(\Delta v_{f} / \Delta \mathrm{TAC}\right)$ is desirable since it implies that the economic value-toinvestment can be recovered through energy recovery.

Combining all the above criteria, $I_{3 E}$ can be derived on the basis of Case 2. It is desirable to have an $I_{3 E}$ as low as possible for a design so that the impacts from energy intensity and GHG intensity are low while positive impact from energy recovery is high. It has been found that series configuration (Cases 2 and 3) has a lower $I_{3 E}$ compared to parallel and parallel-series configurations. For series configuration, Case 3 performs better than Case 2; Case 5 performs better than Case 4 within parallel configuration; while Case 7 performs better than Case 6 within parallel-series configuration. A common feature in Cases 3, 5 and 7 is that recycle configuration is considered in methanol synthesis. Case 3(a) has demonstrated the lowest $I_{3 E}$ among all cases, again in agreement with the results obtained from OB analysis (Table 2 and Fig. 9). This is because Case 3(a) incorporates $90 \%$ recycle for methanol synthesis, while only $10 \%$ is used for electricity generation. This implies that the product value has been increased considerably while only low-cost modification is involved, and also the energy and GHG-intensive power generation process has been avoided. As shown in Table 5, I I $_{\text {E }}$ can be improved (lowered) when ER is considered in Eqs. (11f) and (11g). This shows the importance of improving energy efficiency of a system through energy integration.

\subsection{Remarks}

The current study has shown that $\mathrm{OB}$ analysis appears to give a fairly good prediction in selecting desirable design option. However, the results from $\mathrm{OB}$ analysis should not be taken as the final decision owing to the lack of exactitude in the analysis, which has treated the inner system as a "black-box". IB analysis is a more insightful decision-making tool and it is complement to $\mathrm{OB}$ analysis. It is more comprehensive as it takes into account the energy intensity, GHG intensity and energy recovery into the analysis. The $3 \mathrm{E}$ index, $\mathrm{I}_{3 \mathrm{E}}$ can be employed as an objective function for optimisation problem to minimise the impact of a system. It can be seen from Table 5 that single production system (Cases 0 and 1 ) has a much lower $I_{3 E}$ compared to polygeneration systems (Cases 2-7). It should be noted that it is not sensible to compare the performance of single production system and polygeneration system using the index. The conclusions drawn from current analysis is only applicable for methanol and electricity case. Polygeneration systems with different product combination should be assessed on a case-by-case basis.

\section{Conclusions}

This paper presents a systematic design and decision-making framework which is useful in addressing the challenges in selecting production pathway and system configuration for polygeneration system. The proposed methodology has adopted a well-balanced and multi-dimensional approach considering energy, environmental and economic performances. With the advantages of less data requirement and simplification of the assessment method, the methodology enables effective screening of spectrum of design options and flowsheet configuration at the preliminary stage. Furthermore, the proposed performance metric can be used as a key performance indicator and objective function in optimisation 
problems. It is particularly useful for analysing complex system such as polygeneration system.

Case studies have been conducted on gasification system of which the product synthesis section is the main scope of study. Various configurations such as once-through and recycle in series, parallel and parallel-series domains have been considered for polygeneration of methanol, electricity and heat. The performances of the systems have been analysed and quantified using the proposed 3E metric. This performance metric considers the synergies between the economic worthiness with respect to energy intensity, GHG intensity and potential of energy recovery. It has been found that the polygeneration system with series and recycle configurations has the best $3 \mathrm{E}$ performance for the production of methanol and electricity. The system incorporates $90 \%$ recycle for methanol synthesis, while only $10 \%$ is used for electricity generation. The system has the lowest $3 \mathrm{E}$ index value mainly because the energy and GHG-intensive power generation process has been avoided and $\mathrm{CO}_{2}$ has been captured in the methanol production process, thus reducing both EI and GHGI contributions within the $3 E$ appraisement. From the economic viewpoint, the result indicated by the $3 \mathrm{E}$ index is sensible (i.e. showing that the system is more economically favourable) since methanol production has been enhanced through low-cost modification on the system with high degree of recycling and also utilisation of resources has been improved. In conclusion, it is desirable to have a $3 \mathrm{E}$ index as low as possible for a new or retrofitted design to result in low impacts from energy intensity and GHG intensity domains while positive impact from energy recovery domain. The performance of the system can be improved if energy recovery is considered. Further analysis should be carried out on a case-by-case basis for polygeneration system with different product combination. Hence, there are wider scopes opened up for further research in investigating more complex polygeneration configurations.

\section{References}

Azapagic, A., 2010. Assessing Environmental Sustainability: Life Cycle Thinking and Life Cycle Assessment, in Sustainable Development in Practice. John Wiley \& Sons Ltd, Chichester, UK, pp. 56-80.

Bai, Z., Liu, Q., Lei, J., Li, H., Jin, H., 2015. A polygeneration system for the methanol production and the power generation with the solar-biomass thermal gasification. Energy Convers. Manage. 102, 190-201.

Carvalho, M., Lozano, M.A., Serra, L.M., 2012. Multicriteria synthesis of trigeneration systems considering economic and environmental aspects. Appl. Energy 91 (1), 245-254.

DECC, Department of Energy and Climate Change (DECC), 2014. Quarterly Energy Prices: March 2014, (www.decc.gov.uk〉.

El-Halwagi, M.M., 2012. Sustainable Design through Process Integration - Fundamentals and Applications to Industrial Pollution Prevention, Resource Conservation, and Profitability Enhancement. Butterworth-Heinemann, Elsevier, Oxford.

Gonzalez, M.A., Smith, R.L., 2003. A methodology for the evaluation of process sustainability. Environ. Prog. 22 (4).

Jana, K., De, S., 2015. Techno-economic evaluation of a polygeneration using agricultural residue-a case study for an Indian district. Bioresour. Technol. 181 (0), 163-173.

Kasivisvanathan, H., Barilea, I.D.U., Ng, D.K.S., Tan, R.R., 2013. Optimal operational adjustment in multi-functional energy systems in response to process inoperability. Appl. Energy 102, 492-500.
Khojasteh Salkuyeh, Y., Adams II, T.A., 2015. A novel polygeneration process to co-produce ethylene and electricity from shale gas with zero $\mathrm{CO} 2$ emissions via methane oxidative coupling. Energy Convers. Manage. 92 (0), 406-420.

Klemeš, J., Friedler, F., Bulatov, I., Varbanov, P., 2011. Sustainability in the Process Industry: Integration and Optimization. McGraw-Hill, New York, USA.

Li, Y.-W., Xu, J., Yang, Y., 2010. Diesel from syngas. In: Vertès, A.A., et al. (Eds.), Biomass to Biofuels: Strategies for Global Industries. Wiley, Chichester, UK (Chapter 6).

Liu, P., Gerogiorgis, D.I., Pistikopoulos, E.N., 2007. Modeling and optimization of polygeneration energy systems. Catal. Today 127 (1-4), 347-359.

Lozano, M.A., Carvalho, M., Serra, L.M., 2009. Operational strategy and marginal costs in simple trigeneration systems. Energy 34 (11), 2001-2008.

Lozano, M.A., Carvalho, M., Serra, L.M., 2014. Tackling environmental impacts in simple trigeneration systems operating under variable conditions. Int. J. Life Cycle Assess. 19 (5), 1087-1098.

Martinez-Hernandez, E., Campbell, G., Sadhukhan, J., 2013. Economic value and environmental impact (EVEI) analysis of biorefinery systems. Chem. Eng. Res. Des. 91 (8), 1418-1426.

Martins, A.A., Mata, T.M., Costa, C.A.V., Sikdar, S.K., 2006. Framework for sustainability metrics. Ind. Eng. Chem. Res. 46 (10), 2962-2973.

Methanex, 2014. Methanol Price 30 May 2014, Available from: /www.methanex.com).

Ng, K.S., Sadhukhan, J., 2011. Process integration and economic analysis of bio-oil platform for the production of methanol and combined heat and power. Biomass Bioenergy 35 (3), 1153-1169.

Ng, K.S., Lopez, Y., Campbell, G.M., Sadhukhan, J., 2010. Heat integration and analysis of decarbonised IGCC sites. Chem. Eng. Res. Des. 88 (2), 170-188.

Ng, K.S., Zhang, N., Sadhukhan, J., 2012. A graphical $\mathrm{CO}_{2}$ emission treatment intensity assessment for energy and economic analyses of integrated decarbonised production systems. Comput. Chem. Eng. 45 (0), 1-14.

Ng, K.S., Zhang, N., Sadhukhan, J., 2013. Techno-economic analysis of polygeneration systems with carbon capture and storage and $\mathrm{CO}_{2}$ reuse. Chem. Eng. J. 219 (0), 96-108.

Ng, K.S., 2011. Decarbonised Polygeneration from Fossil and Biomass Resources. In: The University of Manchester, (Ph.D Thesis).

Sadhukhan, J., Ng, K.S., Hernandez, E.M., 2014. Biorefineries and Chemical Processes: Design, Integration and Sustainability Analysis. Wiley, Chichester, UK.

Serra, L.M., Lozano, M.-A., Ramos, J., Ensinas, A.V., Nebra, S.A., 2009. Polygeneration and efficient use of natural resources. Energy 34 (5), 575-586.

Smith, R., 2005. Chemical Process Design and Integration. John Wiley \& Sons Ltd, Chichester, UK.

Sustainable Process Industry through Resource and Energy Efficiency (SPIRE), 2012. SPIRE Vision, Available from: www.spire2030.eu [cited 20147 June].

Tan, R.R., Lam, H.L., Kasivisvanathan, H., Ng, D.K.S., Foo, D.C.Y., Kamal, M., Hallaler, N., Klemeš, J.J., 2012. An algebraic approach to identifying bottlenecks in linear process models of multifunctional energy systems. Theor. Found. Chem. Eng. 46 (6), 642-650.

Tan, R.R., Cayamanda, C.D., Aviso, K.B., 2014. P-graph approach to optimal operational adjustment in polygeneration plants under conditions of process inoperability. Appl. Energy 135 (0), 402-406.

Ubando, A.T., Culaba, A.B., Aviso, K.B., Tan, R.R., 2013. Simultaneous carbon footprint allocation and design of trigeneration plants using fuzzy fractional programming. Clean Technologies and Environmental Policy 15 (5), 823-832.

Wan Alwi, S.R., Manan, Z.A., Klemeš, J.J., Huisingh, D., 2014. Sustainability engineering for the future. J. Cleaner Prod. 71 (0), 1-10. 
Yamashita, K., Barreto, L., 2005. Energyplexes for the 21st century: coal gasification for co-producing hydrogen, electricity and liquid fuels. Energy 30 (13), 2453-2473.

Yi, Q., Feng, J., Wu, Y., Li, W., 2014. 3E (energy, environmental, and economy) evaluation and assessment to an innovative dual-gas polygeneration system. Energy 66 (0), 285-294.

Zhang, J., Ma, L., Li, Z., Ni, W., 2014. The impact of system configuration on material utilization in the coal-based polygeneration of methanol and electricity. Energy 75 (0), 136-145. 